\title{
Salud financiera en créditos hipotecarios mexicanos *
}

\author{
The Financial Health of Mexican Mortgage Loans \\ Héctor Alonso Olivares-Aguayo iD \\ Doctor en Ciencias económicas, Universidad La Salle, \\ Ciudad de México -México, hectoralonso.olivares@lasalle.mx \\ Maivelin Méndez-Molina \\ Licenciada en Actuaría, Instituto Politécnico Nacional, \\ Ciudad de México, México, mmendezm2001@alumno.ipn.mx
}

Eduardo Madrigal-Castillo

Estudiante de licenciatura en Actuaría, Universidad Autónoma del Estado de México, Ciudad de México, México, through-the-fire-and-flames1@hotmail.com

\begin{abstract}
Cómo citar / How to cite
Olivares-Aguayo, H. A.; Méndez-Molina, M.; Madrigal-Castillo, E. (2021). Salud financiera en créditos hipotecarios mexicanos. Revista CEA, v. 7, n. 13, e1530. https://doi.org/10.22430/24223182.1530
\end{abstract}

Recibido: 25 de junio de 2020

Aceptado: 5 de octubre de 2020

\section{Resumen}

Si se desea adquirir un patrimonio familiar, la adquisición de crédito hipotecario conlleva una gran responsabilidad y un análisis previo, , pues la persona debe tener muy claras las condiciones y los factores que influyen cuando las entidades hipotecarias privadas, como las instituciones bancarias, o públicas, como el Instituto del Fondo Nacional de la Vivienda para los Trabajadores (INFONAVIT) y el Fondo de la Vivienda del Instituto de Seguridad y Servicios Sociales de los Trabajadores del Estado (FOVISSSTE) le otorguen el crédito. El principal riesgo se presenta en no poder cumplir con el pago delos intereses periódicos debido al bajo salario mensual que percibe el cliente. El objetivo de este artículo es examinar la salud financiera en créditos hipotecarios mexicanos - públicos y privados - a partir de un estudio de mercado con datos reales del 2015. El método empleado fue cuantitativo experimental y la metodología usada fue de amortización con periodicidad de pagos mensuales. El principal hallazgo de esta investigación se dio a través de evidencia empírica, donde se mostró que la población de clase media baja puede tener un alto riesgo de incumplimiento en sus créditos

\footnotetext{
* Este artículo se deriva del proyecto titulado «Efectos compensatorios de los programas sociales en la desigualdad multidimensional de los hogares de la Ciudad de México analizados mediante minería de datos y redes neuronales artificiales» y ha sido financiado con recursos de la Secretaria de Educación, Ciencia, Tecnología e Innovación de la Ciudad de México (SECTEI).
} 
hipotecarios, dado a que su ingreso mensual va desde \$2103 MXN hasta \$6309 MXN. Por este motivo, la investigación buscó dar a conocer a este tipo de población los factores de riesgo a la hora de adquirir un crédito hipotecario. La conclusión es que únicamente en cuatro escenarios analizados, donde el interés total a pagar es menor al $50 \%$ del valor de la propiedad, el cliente debe destinar al pago de su crédito hipotecario la cantidad de $\$ 10000$ MXN que, a marzo de 2015, equivalía aproximadamente a 4.75 salario mínimo vigente en el Distrito Federal (SMVDF).

Palabras clave: amortización, créditos hipotecarios, pagos, tasa de interés, salud financiera.

Clasificación JEL: E43, F65, G21.

\begin{abstract}
When building a family patrimony, obtaining a mortgage loan takes great responsibility and a previous analysis. Mortgage borrowers should be very clear about the conditions and factors that influence the approval or rejection decisions of private mortgage lenders, such as banking institutions, or public ones; for example, in Mexico, the Fondo Nacional de la Vivienda para los Trabajadores (INFONAVIT) and the Fondo de la Vivienda del Instituto de Seguridad y Servicios Sociales de los Trabajadores del Estado (FOVISSSTE). The main risk is that customers may not be able to pay the periodic interest rate due to their low income. This article aims to examine the financial health of (public and private) Mexican mortgage loans based on a market analysis conducted using real data of 2015. Adopting a quantitative experimental approach, this study implemented a methodology of amortization with periodic monthly installments. The main finding was revealed by empirical evidence, which showed that lower-middle income borrowers may be at a great risk of missing their mortgage payments because their monthly income ranges from MXN \$2,103 to MXN\$6,309. For this reason, the goal of this article is to raise the awareness of this type of customers about the risk factors they should consider when they request a mortgage loan. In conclusion, in only four of the scenarios analyzed in this article, where the total interest to be paid is under $50 \%$ the property value, customers should devote MXN $\$ 10,000$ to the pay the mortgage. As of March 2015, this amount would be approximately 4.75 times the minimum monthly wage in Mexico's Federal District.
\end{abstract}

Keywords: Amortization, mortgage loan, payment, interest rate, financial health.

JEL classification: E43, F65, G21.

\title{
1. INTRODUCCIÓN
}

La importancia de la salud financiera en los hogares del mundo es crucial, pues para ello se deben tener los ingresos suficientes para satisfacer las necesidades básicas de los miembros de la familia, como alimentación, vestido, salud y vivienda (Chin \& Williams, 2020; Shim et al., 2009). Bajo estas circunstancias, el hogar se encuentra en condiciones de bienestar económico; es decir, en situaciones que le permiten vivir con tranquilidad a cada integrante de la familia. No obstante, la mayoría de habitantes de países subdesarrollados cuentan con una mala salud financiera (Carballo \& DalleNogare, 2019). La principal razón es que los salarios son insuficientes para poder cubrir las necesidades básicas en el hogar (Riitsalu \& Põder, 2016). 
México no es la excepción a esta problemática. La mayoría de su población vive en condiciones de pobreza y pobreza extrema; sin embargo, las familias tienen la necesidad de acceder a un hogar para vivir. Dicha necesidad, aunada a la falta de ingresos, conlleva a que el individuo solicite un crédito hipotecario que satisfaga esa necesidad, pero, al no contar con una adecuada salud financiera, los intereses periódicos a pagar pueden ser muy elevados, lo que conllevaría a que la deuda adquirida se dispare, poniendo en riesgo el bienestar económico del hogar. Por eso es importante hacer un análisis en distintos tipos de hipotecarias, tanto públicas como privadas, que ofrecen sus créditos y hacer un estudio previo del mercado para que el individuo pueda tomar la mejor decisión a la hora de adquirir su vivienda, teniendo una capacidad de pago periódica suficiente que no se vea excedida por los intereses y, por ende, una buena salud financiera en el crédito hipotecario adquirido (Bucks et al., 2019).

En México los individuos no tienen una buena salud financiera debido a que no cuentan con una adecuada conciencia por la disciplina del ahorro; tampoco están acostumbrados a planificar correctamente sus decisiones financieras futuras (Amezcua Gracía, et al., 2014; Cosma et al., 2019). Si bien las investigaciones de Boils Morales (2004) y Connolly (1997) muestran que existen apoyos del gobierno mexicano para financiar parte del costo total de la vivienda a través de subsidios, estos apoyos son poco comunes, lo que implica que, en general, los individuos adquieren vivienda sin subsidio alguno y tomen malas decisiones al momento de adquirir el crédito hipotecario al no haber hecho un análisis previo de su capacidad de pago respecto a sus ingresos actuales y del comportamiento de las variables que impactan directamente a éste. Al ser insuficiente el ingreso de los consumidores de dicho crédito, es decir, al no tener el individuo la solvencia suficiente para cubrir los intereses, crece el valor de la deuda adquirida y, por ende, se cae en insolvencia crediticia (Fiebiger \& Lavoie, 2019).

Gómez Martínez et al., (2009) dicen que la tasa de interés es la principal restricción para el individuo al momento de solicitar un crédito hipotecario, pues los cambios que ésta puede tener representan un alto riesgo para el individuo en la hipoteca adquirida, según lo mostrado por (Eichholtz et al., 2019). Cabe recordar que el alza o baja de dicha variable depende de la Junta de Gobierno del Banco de México (Banxico) y en gran medida a las decisiones de política monetaria que toma la Reserva Federal (Fed) de los Estados Unidos. Algunos efectos de esta política se pueden observar en: Albuquerque (2019), Alpanda y Zubairy (2019), Bezemer y Zhang (2019), Dehmej y Gambacorta (2019) y Jarmuzek y Rozenov (2019). Las decisiones que se toman sobre esta política son de alto impacto cuando las tasas de interés son incrementadas, pues el costo del valor de la vivienda crece, ya que dicha tasa representa el costo monetario que Banxico les cobre a los bancos del país por prestar dinero y que estos a su vez lo usen como referencia para cobrar intereses a sus clientes por el financiamiento. Si bien existe el principal antecedente de otorgamiento irracional de créditos hipotecarios durante la crisis subprime en el año 2008, como lo muestran las investigaciones de Akdoğan (2019), Cuevas Ahumada (2011 y 2013), Davis et al., (2019), Luz Juárez et al., (2015), Gerlach-Kristen y Merola (2019), Hossain y Kryzanowski (2019), Justiniano et al., (2019), Martins et al., (2019), Mejía Reyes et al., (2017), Monkkonen (2019), Mykyta (2019), Lenin Navarro Chávez y Zamora Torres (2011), Samaniego (2009), Zurita González y Rodríguez Montoya (2008), Zurita et al., (2009), entre otras, el cliente debe tener precaución en adquirir créditos hipotecarios al observar comportamientos similares de las variables macroeconómicas a las mostradas en 2008, dado que estos comportamientos se pueden repetir y lograr potencializar el valor de la deuda. Lo anterior 
generará una alta probabilidad de incumplimiento en los pagos periódicos de los créditos hipotecarios adquiridos por el cliente.

En este trabajo se destaca la importancia de la salud financiera, lo vital que es para que el cliente no caiga en insolvencia crediticia (Barra \& Zotti, 2019), así como saber utilizar de manera correcta los servicios que se tienen y los riesgos que se contraen al adquirir estos servicios ofrecidos por instituciones financieras privadas (bancarias), tripartita (INFONAVIT) institución tripartita entre: trabajadores, sector empresarial y el gobierno en México, que otorga créditos hipotecarios y no hipotecarios con relación a la vivienda, y gubernamental (FOVISSSTE) órgano gubernamental desconcentrado del Instituto de Seguridad y Servicios Sociales de los Trabajadores del Estado (ISSSTE) y cuya función es proporcionar créditos de vivienda a los trabajadores al servicio del Estado. Las tasas de interés que otorgan las instituciones que ofrecen créditos hipotecarios pueden verse como grandes oportunidades para adquirirlos, pero también pueden generar grandes deudas muy difíciles de pagar para los solicitantes de créditos hipotecarios (clientes). Por lo anterior, la hipótesis para este trabajo de investigación es que la clase media baja no tiene la adecuada capacidad de pago para acceder a créditos hipotecarios mexicanos.

En esta investigación se distinguen los tipos de créditos hipotecarios mexicanos que son ofrecidos a los clientes particularmente a la clase media baja (con información de la Secretaría de Gobernación de México 2013-2018), el ingreso promedio mensual se estimó en \$5 579.88 MXN, lo que equivale a poco más de 2.65 SMVDF, a marzo de 2015), debido a las altas tasas que manejan los créditos hipotecarios bancarios respecto al (Benchmark) Certificados de la Tesorería de la Federación (CETES) 364 días a plazo de un año, que en el mes de marzo de 2015 tuvo un valor de 3.53 \% (Banco de México, 2015). Esta tasa de referencia es la principal en México para que los individuos tomen decisiones de inversión, y para que antes de firmar un contrato con instituciones crediticias, tengan en cuenta factores como: salario mensual del trabajador, tasa de interés efectiva, capacidad de pago y el tiempo en que se desea terminar de liquidar el crédito hipotecario obtenido, es decir, la amortización del crédito hipotecario (término de la deuda adquirida), entre otros. Para llevar a cabo el análisis de esta investigación se muestran 25 escenarios de tablas de amortización para que el cliente pueda observar los resultados previos a su decisión de optar por algún crédito hipotecario. Además, mediante el desarrollo de un programa usando el software DEV C++, se calibra el código con datos reales, considerando las tasas de interés efectivas con periodicidad anual que las instituciones financieras muestran a sus usuarios previamente a la selección de un crédito hipotecario. El programa muestra la cantidad total que pagará el cliente a la fecha de vencimiento de su crédito.

El desarrollo del presente trabajo se compone de las siguientes secciones: crédito hipotecario, metodología de amortización de créditos hipotecarios, resultados, discusión, conclusiones, referencias $y$, finalmente, se presenta en el Anexo la información detallada de las tablas de amortización correspondientes a los 25 escenarios mostrados en la presente investigación y el código desarrollado en DEV C++. 


\section{MARCO TEÓRICO}

\section{Crédito hipotecario}

En un crédito hipotecario, un cliente dispone de una cantidad de dinero comprometiéndose a devolverlo mediante cuotas periódicas junto con los intereses asociados, plasmados en un contrato (Banco Bilbao Vizcaya Argentaria [BBVA], 2019; Wood, 2019).

Es poco común que los individuos cuenten con dinero en efectivo disponible para pagar al contado el crédito hipotecario de su preferencia. Para esto existen instituciones financieras que les otorgan créditos hipotecarios; las principales en México son: FOVISSSTE, INFONAVIT e instituciones bancarias. Generalmente, al solicitar un crédito hipotecario, el cliente se compromete a liquidar la deuda adquirida más intereses al vencimiento del contrato, según las condiciones establecidas en éste. La institución financiera exige una garantía hipotecaria que le asegure el pago del dinero prestado al cliente. Dicha garantía es la hipoteca de la vivienda. Por lo que el beneficiario tendrá que pagar puntualmente en las fechas establecidas en el contrato que acordó con la institución crediticia hasta liquidar su deuda. Existen diversos créditos hipotecarios con distintas tasas de interés, las cuales se pueden adecuar a las necesidades de pago de dicho cliente.

Con información del 2015, las tasas efectivas anuales del INFONAVIT estaban entre $4 \%$ y $10 \%$ dependiendo del número de salarios mínimos que perciba el trabajador (INFONAVIT, 2015). Por su parte, el FOVISSSTE manejaba una tasa efectiva anual del $10.25 \%$. Mientras que el Costo Anual Total (CAT) de los créditos bancarios, en promedio, tenían una es tasa mínima del $10.95 \%$, media $13.17 \%$ y máxima 15.89 \% (Son las tasas promedio a marzo de 2015), donde se percibe que las tasas bancarias son mayores, y no son acordes con la percepción de ingresos de los trabajadores de clase media baja.

A continuación, se muestra la información referente a la cartera de vivienda en cuanto a sus probabilidades de incumplimiento (distribución de frecuencias) con base en lo publicado por la Comisión Nacional Bancaria y de Valores (CNBV) para los principales bancos de México (Banamex, BBVA, Bancomer y Santander) al año 2015. En la Tabla 1, se puede apreciar el número de créditos otorgados por Banamex y su probabilidad de incumplimiento asociada a marzo de 2015.

La Tabla 1, muestra que el mayor número de créditos hipotecarios otorgados por Banamex corresponde a los de adquisición de vivienda nueva con una participación de $65.43 \%$ del total de su cartera de vivienda, de los cuales el $90.59 \%$ tiene una probabilidad de incumplimiento mayor a $0 \%$ hasta $10 \%$. En la Tabla 2, se puede apreciar el número de créditos otorgados por BBVA Bancomer y su probabilidad de incumplimiento asociada a marzo de 2015. 
Tabla 1. Probabilidad de incumplimiento en créditos hipotecarios de Banamex

Table 1. Probability of default in Banamex mortgage loans

\begin{tabular}{|c|c|c|c|c|c|c|c|}
\hline $\begin{array}{c}\text { Probabilidad de } \\
\text { incumplimiento \% }\end{array}$ & $\begin{array}{c}\text { Crédito } \\
\text { antiguo y/o } \\
\text { restructurado }\end{array}$ & $\begin{array}{c}\text { Adquisición } \\
\text { de vivienda } \\
\text { nueva }\end{array}$ & $\begin{array}{c}\text { Adquisición } \\
\text { de vivienda } \\
\text { usada }\end{array}$ & $\begin{array}{c}\text { Pago de } \\
\text { Pasivos } \\
\text { Hipotecarios }\end{array}$ & $\begin{array}{c}\text { Crédito } \\
\text { para } \\
\text { liquidez }\end{array}$ & $\begin{array}{c}\text { Crédito a } \\
\text { exempleados }\end{array}$ & Otros \\
\hline 0 & 0 & 0 & 0 & 0 & 0 & 0 & 0 \\
\hline$(0-10]$ & 447 & 131409 & 65161 & 397 & 6079 & 1591 & 28 \\
\hline$(10-20]$ & 12 & 2770 & 792 & 3 & 70 & 26 & 2 \\
\hline$(20-30]$ & 14 & 2058 & 469 & 1 & 20 & 18 & 1 \\
\hline$(30-40]$ & 1 & 1698 & 357 & 0 & 10 & 1 & 2 \\
\hline$(40-50]$ & 1 & 1602 & 304 & 0 & 3 & 3 & 0 \\
\hline (50-60] & 0 & 1108 & 177 & 0 & 2 & 3 & 0 \\
\hline$(60-70]$ & 0 & 753 & 102 & 0 & 0 & 4 & 0 \\
\hline$(70-80]$ & 0 & 771 & 93 & 0 & 0 & 0 & 0 \\
\hline$(80-90]$ & 1 & 696 & 82 & 0 & 0 & 0 & 0 \\
\hline$(90-100]$ & 3 & 2184 & 315 & 1 & 19 & 10 & 1 \\
\hline Total & 479 & 145049 & 67852 & 402 & 6203 & 1656 & 34 \\
\hline
\end{tabular}

Fuente: elaboración propia con datos de la Comisión Nacional Bancaria y de Valores (CNBV) (2015).

Tabla 2. Probabilidad de incumplimiento en créditos hipotecarios de BBVA Bancomer Table 2. Probability of default in BBVA Bancomer mortgage loans

\begin{tabular}{|c|c|c|c|c|c|c|c|}
\hline $\begin{array}{c}\text { Probabilidad de } \\
\text { incumplimiento \% }\end{array}$ & $\begin{array}{c}\text { Crédito } \\
\text { antiguo y/o } \\
\text { restructurado }\end{array}$ & $\begin{array}{c}\text { Adquisición } \\
\text { de vivienda } \\
\text { nueva }\end{array}$ & $\begin{array}{c}\text { Adquisición } \\
\text { de vivienda } \\
\text { usada }\end{array}$ & $\begin{array}{c}\text { Pago de } \\
\text { Pasivos } \\
\text { Hipotecarios }\end{array}$ & $\begin{array}{c}\text { Crédito } \\
\text { para } \\
\text { liquidez }\end{array}$ & $\begin{array}{c}\text { Crédito a } \\
\text { exempleados }\end{array}$ & Otros \\
\hline 0 & 0 & 0 & 0 & 0 & 0 & 0 & 0 \\
\hline$(0,10]$ & 158130 & 88581 & 20364 & 2383 & 7639 & 2312 & 0 \\
\hline$(10,20]$ & 8177 & 2898 & 426 & 17 & 175 & 63 & 0 \\
\hline$(20,30]$ & 4219 & 1078 & 196 & 3 & 39 & 15 & 0 \\
\hline$(30,40]$ & 1802 & 435 & 67 & 2 & 15 & 6 & 0 \\
\hline$(40,50]$ & 936 & 241 & 30 & 5 & 7 & 3 & 0 \\
\hline$(50,60]$ & 601 & 142 & 32 & 0 & 14 & 3 & 0 \\
\hline$(60,70]$ & 379 & 103 & 40 & 1 & 3 & 2 & 0 \\
\hline$(70,80]$ & 293 & 55 & 12 & 0 & 2 & 0 & 0 \\
\hline$(80,90]$ & 105 & 18 & 0 & 0 & 1 & 0 & 0 \\
\hline$(90,100]$ & 12145 & 2279 & 400 & 20 & 174 & 60 & 0 \\
\hline Total & 186787 & 95830 & 21567 & 2431 & 8069 & 2464 & 0 \\
\hline
\end{tabular}

Fuente: elaboración propia con datos de la Comisión Nacional Bancaria y de Valores (CNBV) (2015).

La Tabla 2, muestra que el mayor número de créditos hipotecarios otorgados por BBVA Bancomer corresponde a los de crédito antiguo y/o restructurado con una participación de $58.25 \%$ del total de su cartera de vivienda, de los cuales el $84.65 \%$ tiene una probabilidad de incumplimiento mayor a 0 
$\%$ hasta $10 \%$. En la Tabla 3, se puede apreciar el número de créditos otorgados por Banco Santander y su probabilidad de incumplimiento asociada a marzo de 2015.

Tabla 3. Probabilidad de incumplimiento en créditos hipotecarios de Santander Table 3. Probability of default in Santander mortgage loans

\begin{tabular}{|c|c|c|c|c|c|c|c|}
\hline $\begin{array}{c}\text { Probabilidad de } \\
\text { incumplimiento \% }\end{array}$ & $\begin{array}{c}\text { Crédito } \\
\text { antiguo y/o } \\
\text { restructurado }\end{array}$ & $\begin{array}{c}\text { Adquisición } \\
\text { de vivienda } \\
\text { nueva }\end{array}$ & $\begin{array}{c}\text { Adquisición } \\
\text { de vivienda } \\
\text { usada }\end{array}$ & $\begin{array}{c}\text { Pago de } \\
\text { Pasivos } \\
\text { Hipotecarios }\end{array}$ & $\begin{array}{c}\text { Crédito } \\
\text { para } \\
\text { liquidez }\end{array}$ & $\begin{array}{c}\text { Crédito a } \\
\text { exempleados }\end{array}$ & Otros \\
\hline 0 & 0 & 3 & 2 & 0 & 0 & 0 & 0 \\
\hline$(0,10]$ & 4930 & 57387 & 42669 & 5782 & 4594 & 2166 & 0 \\
\hline$(10,20]$ & 117 & 1299 & 624 & 20 & 18 & 32 & 0 \\
\hline$(20,30]$ & 38 & 794 & 193 & 8 & 7 & 20 & 0 \\
\hline$(30,40]$ & 12 & 868 & 121 & 6 & 20 & 11 & 0 \\
\hline$(40,50]$ & 10 & 25 & 58 & 3 & 3 & 5 & 0 \\
\hline$(50,60]$ & 6 & 18 & 38 & 1 & 0 & 3 & 0 \\
\hline$(60,70]$ & 0 & 16 & 14 & 1 & 2 & 3 & 0 \\
\hline$(70,80]$ & 0 & 4 & 4 & 0 & 1 & 2 & 0 \\
\hline$(80,90]$ & 0 & 2 & 5 & 0 & 1 & 0 & 0 \\
\hline$(90,100]$ & 316 & 480 & 1259 & 29 & 66 & 122 & 0 \\
\hline Total & 5429 & 60896 & 44987 & 5850 & 4712 & 2364 & 0 \\
\hline
\end{tabular}

La Tabla 3, muestra que el mayor número de créditos hipotecarios otorgados por Santander corresponde a los de adquisición de vivienda nueva con una participación de $47.82 \%$ del total de su cartera de vivienda, de los cuales el $94.23 \%$ tiene una probabilidad de incumplimiento mayor a $0 \%$ hasta $10 \%$. Las cifras mostradas con base en la información de la CNBV, expone que las instituciones bancarias analizadas en este artículo otorgantes de créditos hipotecarios pueden llegar a tener en sus clientes probabilidades muy altas de incumplimiento, es decir, mayores al $90 \%$ hasta $100 \%$.

\section{Metodología de amortización de créditos hipotecarios}

Antes de comprender la metodología empleada para la realización de este trabajo, se expondrá el valor al que converge la serie geométrica (S) siguiente:

$$
\begin{gathered}
S=\sum_{n=0}^{t} X^{n}=1+X+\ldots+X^{t-1}+X^{t} \\
\Rightarrow X S=X \sum_{n=0}^{t} X^{n}=X\left(1+X+\ldots+X^{t-1}+X^{t}\right)=X+\ldots+X^{t}+X^{t+1} \\
S-X S=S(1-X)=1-X^{t+1} \\
\therefore S=\frac{1-X^{t+1}}{1-X},|X| \neq 1
\end{gathered}
$$


La herramienta fundamental son las matemáticas financieras. Para poder comprender el comportamiento de los créditos hipotecarios son las anualidades. Las anualidades más comunes utilizadas en la práctica por las hipotecarias son las anualidades vencidas ya que se consideran pagos al final de cada periodo durante el tiempo de vida del crédito hipotecario otorgado. Para poder encontrar la expresión matemática del valor de dicho crédito se utilizará el valor de convergencia encontrado en la serie geométrica (S) como se muestra en (1). Gráficamente una anualidad vencida se muestra en la línea de tiempo de la Figura 1.

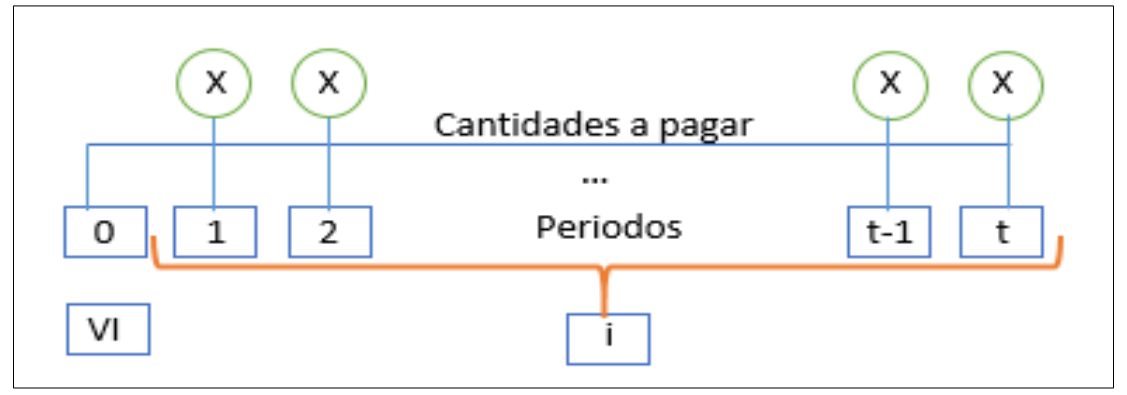

Figura 1. Línea de tiempo de una anualidad vencida

Figure 1. Timeline of an expired annuity Fuente: elaboración propia.

Donde:

X: Cantidad a pagar por periodo durante el tiempo de vida del crédito hipotecario.

t: Número de periodos del crédito hipotecario otorgado.

i: Tasa de interés efectiva por periodo.

VI: Valor del crédito hipotecario.

El valor del crédito hipotecario se encuentra al día de hoy, es decir, a tiempo cero, por lo que cada uno de los pagos futuros se debe traer a valor presente:

$$
V_{i}^{t}=(1+i)^{-t}
$$

El solicitante del crédito hipotecario adquiere derechos y obligaciones; por un lado, tiene el derecho de obtener la vivienda, y por el otro se compromete a realizar sus pagos periódicos para obtenerla. Lo anterior se refleja en la expresión matemática que iguala los derechos con las obligaciones. A esta expresión se le llama ecuación de valor: la ecuación de valor correspondiente a la anualidad vencida reflejada en la línea del tiempo mostrada en la Figura 1 es la siguiente:

$$
\begin{gathered}
V I=X V_{i}^{1}+X V_{i}^{2}+\ldots+X V_{i}^{t-1}+X V_{i}^{t} \\
\Rightarrow V I=X V_{i}^{1}\left(1+\ldots+X V_{i}^{t-1}\right) \\
\Rightarrow V I=X V_{i}^{1}\left(\frac{1-V_{i}^{t}}{1-V_{i}^{1}}\right)
\end{gathered}
$$




$$
\begin{gathered}
\Rightarrow V I=X(1+i)^{-1}\left(\frac{1-\left((1+i)^{-t}\right)}{1-\left(\frac{1}{1+i}\right)}\right) \\
\Rightarrow V I=X(1+i)^{-1}\left(\frac{1-\left((1+i)^{-t}\right)}{\frac{i}{1+i}}\right) \\
\Rightarrow V I=X\left(\frac{1-\left((1+i)^{-t}\right)}{i}\right)
\end{gathered}
$$

De las ecuaciones (2) y (3) se observa que el valor del crédito hipotecario depende de: la cantidad a pagar, la tasa de interés efectiva por periodo y del tiempo en número de periodos a liquidar la deuda. Para poder liquidar los créditos hipotecarios analizados en esta investigación se tuvieron que construir tablas de amortización liquidación de un crédito (Cánovas Theriot, 2004), donde se programó la construcción de estas tablas en DEV C++ (en la parte final del Anexo se muestra el código).

Lo anterior se puede resumir en la tabla de amortización, la cual, para cada periodo de tiempo muestra el Saldo Insoluto (SI) justo después del pago correspondiente. Los intereses sobre dicho saldo (I) y la amortización pagada (A). Esta tabla de amortización, de forma más general, se muestra en la Tabla 4.

Tabla 4. Tabla de amortización en t periodos

Table 4. Table of amortization into t periods

\begin{tabular}{ccccc}
\hline Número de meses & Pago por meses & $\begin{array}{c}\text { Intereses sobre el } \\
\text { saldo insoluto }\end{array}$ & Amortización & Saldo Insoluto \\
\hline 0 & -- & -- & -- & $\mathrm{SI}_{0}=\mathrm{VI}$ \\
\hline 1 & $\mathrm{X}_{1}$ & $\mathrm{I}_{1}=\left(\mathrm{SI}_{\mathrm{O}}\right)^{*}(\mathrm{i})$ & $\mathrm{A}_{1}=\mathrm{X}_{1}-\mathrm{I}_{1}$ & $\mathrm{SI}_{1}=\mathrm{SI}_{0}-\mathrm{A}_{1}$ \\
\hline 2 & $\mathrm{X}_{2}$ & $\mathrm{I}_{2}=\left(\mathrm{SI}_{1}\right)^{*}(\mathrm{i})$ & $\mathrm{A}_{2}=\mathrm{X}_{2}-\mathrm{I}_{2}$ & $\mathrm{SI}_{2}=\mathrm{SI}_{1}-\mathrm{A}_{2}$ \\
\hline$\cdot$ & $\cdot$ & $\cdot$ & $\cdot$ & $\cdot$ \\
\hline$\cdot$ & $\cdot$ & $\cdot$ & $\cdot$ & $\cdot$ \\
\hline $\mathrm{t}-1$ & $\cdot$ & $\cdot$ & $\mathrm{A}_{\mathrm{t}-1}=\mathrm{X}_{\mathrm{t}-1}-\mathrm{I}_{\mathrm{t}-1}$ & $\mathrm{SI}_{\mathrm{t}-1}=\mathrm{SI}_{\mathrm{t}-2}-\mathrm{A}_{\mathrm{t}-1}$ \\
\hline $\mathrm{t}$ & $\mathrm{X}_{\mathrm{t}-1}$ & $\mathrm{I}_{\mathrm{t}-1}=\left(\mathrm{SI} \mathrm{I}_{\mathrm{t}-2}\right)^{*}(\mathrm{i})$ & $\mathrm{SI}_{\mathrm{t}}=\mathrm{SI}_{\mathrm{t}-1}-\mathrm{A}_{\mathrm{t}}$ \\
\hline
\end{tabular}

Se nota que, en este método en general los pagos pueden ser distintos en cada periodo, la única condición que se le pide a los pagos es que en valor presente cubran el préstamo más intereses.

\section{METODOLOGÍA}

En esta investigación, de tipo cuantitativa experimental, el proceso de indagación se realizó de la siguiente manera: primero se inició una búsqueda en páginas oficiales de hipotecarias mexicanas tanto públicas (INFONAVIT y FOVISSSTE) como privadas (Instituciones bancarias) a través de la CNBV; posteriormente se procedió a descargar los datos reales publicados - a marzo de 2015 - de las tasas de interés efectivas, Saldo Insoluto inicial de la vivienda y pagos periódicos según el tipo de producto ofrecido a los clientes. Una vez que la información fue homologada, se analizaron 241 escenarios 
mediante la construcción de tablas de amortización desarrolladas a través de un programa en DEV C++ para obtener los valores de la cantidad total a pagar, los intereses totales pagados y la amortización obtenida medida en años; es decir, el algoritmo determinó el tiempo exacto en el que el cliente terminará de liquidar su crédito hipotecario al realizar su último pago. Esta información fue exportada a Excel.

\section{RESULTADOS}

El resumen de los resultados obtenidos, ordenados de menor a mayor en cuanto al tiempo en que el cliente con una adecuada capacidad de pago terminará de liquidar su deuda para los distintos tipos de créditos, en todos los casos con un Saldo Insoluto inicial de \$620 000 MXN, se muestran en la Tabla 5.

Tabla 5. Resultados de los créditos hipotecarios analizados

Table 5. Results of the mortgage loans under analysis

\begin{tabular}{|c|c|c|c|c|c|}
\hline Caso & $\begin{array}{l}\text { Valor del } \\
\text { crédito } \\
\text { hipotecario } \\
(\mathrm{MXN})\end{array}$ & $\begin{array}{l}\text { Interés total del } \\
\text { crédito } \\
\text { hipotecario } \\
(\mathrm{MXN})\end{array}$ & $\begin{array}{l}\text { Pago total del } \\
\text { crédito } \\
\text { hipotecario } \\
(\mathrm{MXN})\end{array}$ & $\begin{array}{l}\text { Amortización del } \\
\text { crédito hipotecario } \\
\text { en años }\end{array}$ & $\begin{array}{c}\text { Tipo de } \\
\text { crédito hipotecario }\end{array}$ \\
\hline 1 & $\$ 620000.00$ & $\$ 235986.10$ & $\$ 855986.10$ & 7.16 & INFONAVIT escenario 14 \\
\hline 2 & $\$ 620000.00$ & $\$ 256098.57$ & $\$ 876098.57$ & 7.33 & INFONAVIT escenario 17 \\
\hline 3 & $\$ 620000.00$ & $\$ 266666.25$ & $\$ 886666.25$ & 7.41 & FOVISSSTE escenario 3 \\
\hline 4 & $\$ 620000.00$ & $\$ 298291.22$ & $\$ 918291.22$ & 7.66 & $\begin{array}{l}\text { Bancario tasa mínima } \\
\text { promedio escenario } 3\end{array}$ \\
\hline 5 & $\$ 620000.00$ & $\$ 425198.59$ & $\$ 1045198.59$ & 8.75 & $\begin{array}{l}\text { Bancario tasa media } \\
\text { promedio escenario } 1\end{array}$ \\
\hline 6 & $\$ 620000.00$ & $\$ 687732.94$ & $\$ 1307732.94$ & 10.91 & $\begin{array}{l}\text { Bancario tasa máxima } \\
\text { promedio escenario } 1\end{array}$ \\
\hline 7 & $\$ 620000.00$ & $\$ 498389.06$ & $\$ 1118389.06$ & 14.41 & INFONAVIT escenario 7 \\
\hline 8 & $\$ 620000.00$ & $\$ 511691.13$ & $\$ 1131691.13$ & 14.58 & INFONAVIT escenario 9 \\
\hline 9 & $\$ 620000.00$ & $\$ 525487.73$ & $\$ 1145487.73$ & 14.75 & INFONAVIT escenario 11 \\
\hline 10 & $\$ 620000.00$ & $\$ 539810.97$ & $\$ 1159810.97$ & 14.91 & INFONAVIT escenario 13 \\
\hline 11 & $\$ 620000.00$ & $\$ 620757.69$ & $\$ 1240757.69$ & 15.91 & INFONAVIT escenario 16 \\
\hline 12 & $\$ 620000.00$ & $\$ 668492.51$ & $\$ 1288492.51$ & 16.58 & FOVISSSTE escenario 2 \\
\hline 13 & $\$ 620000.00$ & $\$ 577798.50$ & $\$ 1197798.50$ & 16.66 & INFONAVIT escenario 4 \\
\hline 14 & $\$ 620000.00$ & $\$ 595677.58$ & $\$ 1215677.58$ & 16.91 & INFONAVIT escenario 5 \\
\hline 15 & $\$ 620000.00$ & $\$ 614414.52$ & $\$ 1234414.52$ & 17.16 & INFONAVIT Escenario 6 \\
\hline 16 & $\$ 620000.00$ & $\$ 634083.92$ & $\$ 1254083.92$ & 17.50 & INFONAVIT escenario 8 \\
\hline 17 & $\$ 620000.00$ & $\$ 654785.85$ & $\$ 1274785.85$ & 17.75 & INFONAVIT escenario 10 \\
\hline 18 & $\$ 620000.00$ & $\$ 676601.04$ & $\$ 1296601.04$ & 18.08 & INFONAVIT escenario 12 \\
\hline 19 & $\$ 620000.00$ & $\$ 842050.79$ & $\$ 1462050.79$ & 18.75 & $\begin{array}{l}\text { Bancario tasa mínima } \\
\text { promedio escenario } 2\end{array}$ \\
\hline 20 & $\$ 620000.00$ & $\$ 807255.10$ & $\$ 1427255.10$ & 19.83 & INFONAVIT escenario 15 \\
\hline 21 & $\$ 620000.00$ & $\$ 891396.09$ & $\$ 1511396.09$ & 21 & FOVISSSTE escenario 1 \\
\hline 22 & $\$ 620000.00$ & $\$ 1271261.63$ & $\$ 1891261.63$ & 26.33 & $\begin{array}{l}\text { Bancario tasa mínima } \\
\text { promedio escenario } 1\end{array}$ \\
\hline 23 & $\$ 620000.00$ & $\$ 966856.32$ & $\$ 1586856.32$ & 26.50 & INFONAVIT escenario 1 \\
\hline 24 & $\$ 620000.00$ & $\$ 1022747.83$ & $\$ 1642747.83$ & 27.41 & INFONAVIT escenario 2 \\
\hline 25 & $\$ 620000.00$ & $\$ 1159481.63$ & $\$ 1779481.63$ & 29.66 & INFONAVIT escenario 3 \\
\hline
\end{tabular}


Analizando la Tabla 5, que es un resumen de los resultados mostrados en esta investigación, se observa que, de los 25 escenarios mostrados, los 3 escenarios correspondientes a créditos hipotecarios otorgados por el FOVISSSTE ocupan los lugares 3, 12 y 21, por lo que, al comparar cada escenario, se observa lo siguiente:

En el escenario 1, el cliente termina de liquidar exactamente su deuda en 252 meses, que equivalen a 21 años; 53 meses más, es decir, a 4.41 años respecto al escenario 2, y con un pago total de intereses mayor por la cantidad de \$222903.58 MXN. En cuanto al escenario 3, las diferencias se observan mucho más grandes, pues en este escenario el cliente termina de liquidar su deuda en 89 meses, es decir, 163 meses menos, que equivalentes a 13.58 años, y con un pago de intereses totales menor por la cantidad de $\$ 624729.83$ MXN (esta cantidad de intereses es mayor que el costo inicial del valor del crédito hipotecario adquirido).

Ahora bien, como en el escenario 2 el cliente liquida su deuda en 199 meses (16.58 años), y en el escenario 3 la deuda es liquidada en 89 meses, que corresponden a 7.41 años, se observa que el escenario 3 es mejor que el escenario 2, ya que se muestra una diferencia de 110 meses, equivalentes a 9.16 años, además que la cantidad del interés pagado es menor por \$401 826.25 MXN (dicho proceso lo podrán observar con detalle en las Tablas 6,7 y 8 del Anexo).

Los resultados de los tres escenarios analizados para el crédito hipotecario bancario con tasa mínima ocupan los lugares 4, 19 y 22. Al comparar cada escenario se muestra lo siguiente: en el escenario 1 , el cliente termina de liquidar exactamente su deuda en 316 meses (26.33 años), 91 meses más (7.58 años) con respecto al escenario 2, y con un pago total de intereses mayor por la cantidad de \$429 210.84 MXN. En relación al escenario 3, las diferencias se observan mucho más grandes, pues en este escenario el cliente termina de liquidar su deuda en 92 meses, es decir 224 meses menos, que equivalen a 18.66 años, y con un pago de intereses totales menor por la cantidad de $\$ 972970.41$ MXN.

Entonces, como en el escenario 2 el cliente liquida su deuda en 225 meses, (18.75 años), y en el escenario 3 la deuda es liquidada en 92 meses, (7.66 años), se observa que el escenario 3 es mejor que el escenario 2 ya que se muestra una diferencia de 133 meses, equivalentes a 11.08 años; además, la cantidad del interés pagado es menor por \$543 759.57 MXN (véase las Tablas 9,10 y 11 del Anexo, para un mayor detalle).

Asimismo, en los otros 2 escenarios correspondientes a créditos hipotecarios bancarios, pero en los casos de tasa media y máxima (se puede apreciar a detalle la evolución de dichos créditos respectivamente en las Tablas 12 y 13 del Anexo) ocupan los lugares 5 y 6 , respectivamente; al comparar cada escenario con el mejor escenario de tasa mínima anteriormente mostrado, se tiene lo siguiente: para el escenario de tasa media el cliente termina de liquidar exactamente su deuda en 105 meses, es decir, 8.75 años, 13 meses más que equivalen a 1.08 años respecto al mejor escenario de tasa mínima, y con un pago total de intereses mayor por la cantidad de \$126907.37 MXN. Respecto al escenario de tasa máxima, las diferencias se observan más grandes, pues en este escenario el cliente termina de liquidar su deuda en 131 meses, lo que significa 39 meses más (3.25 años), en relación con el mejor escenario de tasa mínima y con un pago total de intereses mayor por la cantidad de \$389441.72 MXN. Por lo anterior, es claro que, de los cinco escenarios correspondientes al tipo de crédito hipotecario bancario, el mejor es el de tasa mínima. 
En el caso de INFONAVIT se analizaron 17 escenarios más (para mayor detalle ver las Tablas 14 a 30 del Anexo); sin embargo, se explicarán por fines prácticos solamente los escenarios extremos, es decir, el mejor y el peor escenario, respectivamente, correspondientes al lugar 1 y 25 mostrados en la Tabla 5. Los resultados del peor escenario que se muestra en esta investigación corresponden a INFONAVIT (escenario 3) donde el cliente termina de liquidar exactamente su deuda en 356 meses, que equivalen a 29.66 años (muy cerca del tiempo límite establecido por Ley que es de 30 años); 270 meses más, que equivalen a 22.5 años respecto al mejor escenario que corresponde a INFONAVIT (escenario 14) y con un pago total de intereses mayor por la cantidad de \$923 $495.53 \mathrm{MXN}$. Lo anterior muestra que para el tipo de crédito INFONAVIT el mejor escenario de todos los analizados, corresponde al 14; de hecho, es el mejor escenario mostrado en esta investigación comparado también con los tipos de crédito hipotecarios FOVISSSTE y bancarios.

\section{DISCUSIÓN}

Si bien existen modelos más robustos para la medición del riesgo de crédito en investigaciones como las de Módica-Milo et al., (2012), Longstaff y Schwartz (1995), Merton (1974) y Ohlson (1980), en este trabajo se muestra una forma sencilla de concientizar a la población mexicana, particularmente a la clase media baja, del riesgo de incumplimiento del crédito adquirido a través de la metodología de amortización. En este trabajo se analizaron diversos escenarios mediante la construcción de 241 tablas de amortización. Los números reflejan que en el $89.50 \%$ de las tablas realizadas, el pago mensual de los clientes no cubre los intereses del crédito hipotecario de manera periódica, lo cual lleva a que éste se dispare y que la deuda crezca mes a mes, pues la amortización es nula para estos casos. Dichos escenarios no son viables para el cliente, pero sí lo son para las instituciones financieras otorgantes del crédito hipotecario. Por otro lado, únicamente el $10.50 \%$ de los escenarios realizados reflejan que los clientes pueden terminar de liquidar su deuda en un tiempo entre los 7 y los 30 años, al invertir su dinero en una propiedad realizando pagos mensuales principalmente por las cantidades de $\$ 5000$ MXN, \$6000 MXN y \$6500 MXN (véase el detalle en el Anexo en las Tablas 6, 7, 9, 10, de la 14 a la 26 y la 28 y 29). Cabe resaltar que, si bien las cantidades de pago se observan con poca diferencia, realmente el resultado final de la cantidad de intereses totales pagados y el tiempo de liquidación de la deuda adquirida es significativo para el cliente.

Los mejores resultados de esta investigación únicamente corresponden a cuatro escenarios del total analizado, donde el interés total a pagar es menor al 50\% del valor de la propiedad. Para ello se observó que el cliente debe destinar al pago de su crédito hipotecario la cantidad de \$10 000 MXN, que aproximadamente equivale a 4.75 SMVDF a marzo de 2015. Sin embargo, para un cliente de clase media baja tener una capacidad de pago mensual a las cantidades anteriormente mencionadas es muy complicado, aunado a que muy probablemente también el cliente tenga sus gastos familiares.

Góngora Pérez (2014) dice «el aumento del desempleo, la inflación y las tasas de interés, suelen estar acompañadas por el incremento de la cartera vencida de los créditos generados, debido a la falta de capacidad de pago por parte de los deudores bancarios» (p. 7). Este tipo de factores alteran de manera negativa la estabilidad del sistema financiero mexicano. Por lo que, en este trabajo, se demuestra la importancia de un previo análisis de escenarios, ya que si bien se desea adquirir un patrimonio familiar (vivienda), el cliente debe tener claro las condiciones y los factores que influyen en la contratación de su crédito hipotecario, donde el principal riesgo para el cliente de clase media 
baja es que los intereses periódicos no puedan ser cubiertos, derivado esto del bajo salario mensual que percibe.

Existen diversas instituciones que consideran tasas de interés y periodicidad de pago distintas. ¿Pero entre tantas opciones cómo saber qué decisión tomar? Este artículo muestra una cantidad finita de 25 escenarios apoyado del código DEV C++, ayudando al posible cliente a tener una visión más clara del comportamiento que tienen los créditos hipotecarios, y de esta manera observar si su capacidad de pago le permite ser acreedor de alguno, cuidando siempre su salud financiera.

Precisamente, como actualmente en México existen personas de clase media baja con una inadecuada capacidad de pago para hacer frente a un crédito hipotecario, pues su bajo salario no alcanza a cubrir los intereses periódicos de dicho crédito, se ha creado el programa «Responsabilidad Compartida», del INFONAVIT, que opera a partir del año 2019. El objetivo del programa es apoyar a los trabajadores que menos tienen y más lo necesitan, considerando los siguientes requisitos: contar con un crédito tradicional vigente en Veces Salario Mínimo (VSM), ganar hasta cuatro salarios mínimos, ser mayor de 40 años, tener 24 meses de pagos continuos, un crédito hipotecario con duración de al menos 15 años, que se deba 1.5 veces más de la deuda adquirida inicialmente por el cliente y que éste pague por vía nómina o cuenta al (INFONAVIT, 2019). Este programa es impulsado por el actual gobierno a través del presidente Andrés Manuel López Obrador, quien indica que se podrá tener un descuento hasta del 55\% del total del Saldo Insoluto del crédito hipotecario, pues existen casos reales en que la deuda de dicho crédito hipotecario se ha incrementado hasta cinco veces (Excélsior, 2019).

\section{CONCLUSIONES}

En los 241 escenarios totales de esta investigación, los números reflejan que el $83.5 \%$ de los clientes liquidarán su deuda en el plazo máximo - que es de 30 años en México -, y el 16.5\% terminarán de pagarla en un plazo menor; sin embargo, únicamente el 1.65\%, que equivale a 4 escenarios, el interés total a pagar es menor al $50 \%$ del valor de la propiedad con pagos periódicos mensuales del cliente de $\$ 10000$ MXN. Se analizaron créditos hipotecarios de clientes que, a marzo de 2015, destinan de su ingreso de 1 hasta 4.75 SMVDF, donde los resultados muestran que en clientes de clase media baja que tienen un ingreso mensual de $\$ 2103$ MXN hasta $\$ 6309$ MXN, dicho ingreso no es suficiente para poder pagar su crédito hipotecario; es decir, no se tiene la capacidad de pago necesaria para cubrir al menos los intereses generados en el periodo mensual por la adquisición de dicho crédito. Por lo anterior, se muestran en resumen únicamente los resultados de 25 escenarios, correspondientes a las tablas de amortización para clientes que destinan en sus pagos $\$ 5000 \mathrm{MXN}$, $\$ 6000$ MXN, \$6500 MXN y \$10 000 MXN de su ingreso. Observando que en todos los escenarios cuando el pago es justo de $\$ 5000 \mathrm{MXN}$, la deuda se termina de liquidar en un intervalo de tiempo de 26.50 a 29.66 años.

Este trabajo considera tablas de amortización con pagos constantes de forma mensual; sin embargo, la mayoría de las veces la cantidad abonada a capital (valor actual de la deuda) de este tipo de pagos es pequeña. Por tal motivo, para futuras investigaciones se pueden realizar escenarios donde la amortización periódica sea constante y se destine una mayor cantidad de cada pago periódico a capital y por ende la deuda decrezca más rápidamente. Asimismo, se propone como línea de 
investigación futura amortizaciones donde los pagos periódicos a realizar sean distintos, adaptándose así a las necesidades que tenga el acreedor del crédito hipotecario.

A diferencia de otras investigaciones, el valor agregado de esta investigación es que muestra un algoritmo útil y de fácil uso que pueda ser implementado en la práctica, no solo en México, sino en cualquier parte del mundo, para que los individuos puedan realizar comparativos de los productos públicos o privados que le son ofrecidos por las hipotecarias a través de diversos escenarios de adquisición de vivienda y puedan optar por la mejor decisión sujeta a su capacidad de pago.

\section{AGRADECIMIENTOS}

Agradecemos a la Secretaría de Ciencia, Tecnología, Educación e Innovación de la Ciudad de México (SECTEI) y al Consejo Nacional de Ciencia y Tecnología (CONACYT) por el apoyo para la realización de este trabajo.

\section{CONFLICTOS DE INTERÉS}

Los autores declaran que no presentan conflictos de interés financiero, profesional o personal que pueda influir de forma inapropiada en los resultados obtenidos o las interpretaciones propuestas.

\section{CONTRIBUCIÓN DE AUTORES}

Para el desarrollo de este proyecto todos los autores han realizado una contribución significativa especificada a continuación:

Héctor Alonso Olivares-Aguayo: conceptualización, análisis formal, investigación, validación, redacción de revisión y edición.

Maivelin Méndez-Molina: curación de datos, análisis formal, investigación, metodología, redacción de revisión y edición.

Eduardo Madrigal-Castillo: análisis formal, metodología, visualización, redacción del borrador original.

\section{REFERENCIAS}

Akdoğan, K. (2019). Size and sign asymmetries in house price adjustments. Applied Economics, v. 51, n. 48, 5268-5281. https://doi.org/10.1080/00036846.2019.1612030

Albuquerque, B. (2019). One Size Fits All? Monetary Policy and Asymmetric Household Debt Cycles in U.S. States. Journal of Money, Credit and Banking, v. 51, n. 5, 1309-1353.

https://doi.org/10.1111/jmcb.12547 
Alpanda, S.; Zubairy, S. (2019). Household Debt Overhang and Transmmision of Monetary Policy. Journal of Money, Credit and Banking, v. 51, n. 5, 1265-1307. https://doi.org/10.1111/jmcb.12548

Amezcua Gracía, E. L.; Arroyo Grant, M. G.; Espinoza Mejía, F. (2014). Contexto de la educación financiera en México. Ciencia Administrativa, n. 1, 21-30. URL

Banco Bilbao Vizcaya Argentaria (2019). Crédito hipotecario: definición y tipos. $\underline{\text { URL }}$

Banco de México (2015). Reformas al sistema financiero durante el 2015. URL

Barra, C.; Zotti, R. (2019). Market power and stability of financial institutions: evidence from the Italian banking sector. Journal of Financial Regulation and Compliance, v, 28, n. 2, 1-33. https://doi.org/10.1108/JFRC-05-2019-0055

Bezemer, D.; Zhang, L. (2019). Credit composition and the severity of post-crisis recessions. Journal of Financial Stability, v. 42, 52-66. https://doi.org/10.1016/i.jfs.2019.05.010

Boils Morales, G. (2004). El Banco Mundial y la política de vivienda en México. Revista Mexicana de Sociología, v. 66, n. 2, 345-367. URL

Bucks, B.; Critchfield, T.; Singer, S. (2019). National Survey of Mortgage Originations Survey Data on Your Home Loan Toolkit. Cityscape, v. 21, n. 2, 75-90. URL

Cánovas Theriot, R. (2004). Matemáticas financieras: fundamentos y aplicaciones. Trillas.

Carballo, I. E.; Dalle-Nogare, F. (2019). Fintech e inclusión financiera: los casos de México, Chile y Perú. Revista CEA, v. 5, n. 10, 11-34. https://doi.org/10.22430/24223182.1441

Chin, A.; Williams, A. K. (2020). Take-up of financial education: Demographic characteristics and prior knowledge. Journal of Public Policy \& Marketing, v. 39, n. 3, 319-333. https://doi.org/10.1177/0743915619858928

Comisión Nacional Bancaria y de Valores (2015). Información de las características de la cartera de crédito, cartera de vivienda. $\underline{\mathrm{URL}}$

Connolly, P. (1997). El financiamiento de vivienda en México. URL

Cosma, S.; Cosma, S.; Peluso, A. M. (2019). Determinants of older consumers' interest in home equity conversion products. International Journal of Bank Marketing, v. 37, n. 5, 1275-1295. https://doi.org/10.1108/IJBM-11-2018-0312

Cuevas Ahumada, V. M. (2011). México y Canadá ante la crisis financiera estadounidense: un estudio comparativo. Economía UNAM, v. 8, n. 24, 51-77. URL 
Cuevas Ahumada, V. M. (2013). La crisis hipotecaria subprime y sus efectos sobre México. Análisis Económico, v. 28, n. 67, 123-151. URL

Davis, E. P.; Liadze, I.; Piggot, R. (2019). Assessing the macroeconomic impact of alternative macroprudential policies. Economic Modeling, v. 80, 407-428. https://doi.org/10.1016/j.econmod.2018.11.025

Dehmej, S.; Gambacorta, L. (2019). Macroprudential Policy in a Monetary Union. Comparative Economic Studies, v. 61, n. 2, 195-212. https://doi.org/10.1057/s41294-019-00085-0

Eichholtz, P.; Holtermans, R.; Kok, N.; Yönder, E. (2019). Environmental performance and the cost of debt: Evidence from commercial mortgages and REIT bonds. Journal of Banking and Finance, v. 102, 19-32. https://doi.org/10.1016/i.jbankfin.2019.02.015

Excélsior (19 de diciembre del 2019). Infonavit te ayuda con descuentos de hasta 55\%; ve los requisitos. $\underline{\mathrm{URL}}$

Fiebiger, B.; Lavoie, M. (2019). Trend and business cycles with external markets: Non-capacity generating semiautonomous expenditures and effective demand. Metroeconomica, v. 70, n. 2, 247-262. https://doi.org/10.1111/meca.12192

Fondo de la Vivienda al Instituto de Seguridad y Servicios Sociales de los Trabajadores del Estado (2015). ACUERDO 63.1349.2015 mediante el cual se aprueba el Reglamento Orgánico del Fondo de la Vivienda del Instituto de Seguridad y Servicios Sociales de los Trabajadores del Estado. URL

Gerlach-Kristen, P.; Merola, R. (2019). Consumption and credit constraints: a model and evidence from Ireland. Empirical Economics, v. 57, n. 2, 475-503.

https://doi.org/10.1007/s00181-018-1461-4

Gómez Martínez, A.; García Pérez de Lema, D.; Marín Hernández, S. (2009). Restricciones a la financiación de la PYME en México: una aproximación empírica. Análisis Económico, v. 24, n. 57, 217-238. URL

Góngora Pérez, J. P. (2014). Morosidad de la cartera crediticia en México. Comercio Exterior, v. 64, n. 2, 6-10. $\underline{U R L}$

Hossain, A.T.; Kizanowski, L. (2019). Global financial crisis after ten years: A review of the causes and regulatory reactions. Managerial Finance, v. 45, n. 7, 904-924.

https://doi.org/10.1108/MF-09-2018-0453

Instituto del Fondo Nacional de la Vivienda para los Trabajadores (2019). ¿Qué es el programa Responsabilidad Compartida Infonavit? $\underline{\text { URL }}$

Instituto del Fondo Nacional de la Vivienda para los Trabajadores (2015). Instituto del Fondo Nacional de la Vivienda para los Trabajadores. URL 
Jarmuzek, M.; Rozenov, R. (2019). Excessive private sector leverage and its drivers: Evidence from advanced economies. Applied Economics, v. 51, n. 34, 3787-3803. https://doi.org/10.1080/00036846.2019.1584383

Justiniano, A.; Primiceri, G. E.; Tambalotti, A. (2019). Credit supply and the housing boom. Journal of Political Economy, v. 127, n. 3, 1317-1350. https://doi.org/10.1086/701440

Lenin Navarro Chávez, J. C.; Zamora Torres, A. I. (2011). La crisis económica internacional y sus efectos en México y Michoacán. Inceptum, v. 6, n. 11, 315-330. URL

Longstaff, F. A.; Schwartz, E. S. (1995). A simple approach to valuing risky fixed and floating rate debt. The Journal of Finance, v. 50, n. 3,789-819. https://doi.org/10.1111/j.1540-6261.1995.tb04037.x

Luz Juárez, G.; Sánchez Daza, A.; Zurita González, J. (2015). La crisis financiera internacional de 2008 y algunos de sus efectos económicos sobre México. Contaduría y Administración, v. 60, s. 2, 128146. http://dx.doi.org/10.1016/j.cya.2015.09.011

Martins, A. M.; Serra, A.P.; Stevenson, S. (2019). Determinants of real estate bank profitability. Research in International Business and Finance, v. 49, 282-300. https://doi.org/10.1016/i.ribaf.2019.04.004

Mejía Reyes, P.; Ángel Díaz, M.; Vergara González, R. (2017). Recesiones de México en los albores del siglo XXI. Revista Problemas del Desarrollo, v. 48, n. 189, 57-84. https://doi.org/10.22201/iiec.20078951e.2017.189.56947

Merton, R. C. (1974). On the pricing of corporate debt: The risk structure of interest rates. Journal of Finance, v. 29, n. 2, 449-470. https://doi.org/10.1111/j.1540-6261.1974.tb03058.x

Módica-Milo, A.; Baixauli, J. S.; Alvarez, S. (2012). Propuesta de un indicador de salud financiera y su efecto en la predicción del fracaso empresarial. Revista Internacional Administración \& Finanzas, v. 5, n. $3,19-40 . \underline{U R L}$

Monkkonen, P. (2019). Empty houses across North America: Houssing finance and Mexico's vacancy crisis. Urban Studies, v. 56, n. 10, 2075-2091. https://doi.org/10.1177\%2F0042098018788024

Mykyta, L. (2019). Houssing crisis, hardship and safety net support: Examining the effects of foreclosure on households and families. Housing Studies, v. 34, n. 5, 827-848. https://doi.org/10.1080/02673037.2018.1487040

Ohlson, J. A. (1980). Financial ratios and the probabilistic prediction of bankruptcy. Journal of Accounting Research, v. 18, n. 1, 109-131. https://doi.org/10.2307/2490395

Riitsalu, L.; Põder, K. (2016). A glimpse of the complexity of factors that influence financial literacy. International Journal of Consumer Studies, v. 40, n. 6, 722-731. https://doi.org/10.1111/ijcs.12291 
Samaniego, N. (2009). La crisis, el empleo y los salarios en México. Economía UNAM, v. 6, n. 16, 5767. $\underline{U R L}$

Secretaría de Gobernación. (2013). ACUERDO por el que se aprueba el Programa Nacional de Protección a los Derechos del Consumidor 2013-2018. URL

Shim, S.; Xiao, J. J.; Barber, B. L.; Lyons, A. C. (2009). Pathways to life success: A conceptual model of financial well-being for young adults. Journal of Applied Developmental Psychology, v. 30, n. 6, 708-723. https://doi.org/10.1016/i.appdev.2009.02.003

Wood, J. D. G. (2019). Mortgage Credit: Denmark's Financial Capacity Building Regime. New Political Economy, v. 24, n. 6, 833-850. https://doi.org/10.1080/13563467.2018.1545755

Zurita González, J.; Martínez Pérez, J. F.; Rodríguez Montoya, F. (2009). La crisis financiera y económica del 2008. Origen y consecuencias en los Estados Unidos y México. El Cotidiano, n. 157, 17-27. URL

Zurita González, J.; Rodríguez Montoya, J. F. (2008). La crisis de los créditos hipotecarios en Estados Unidos: algunas consideraciones. Análisis Económico, v. 23, n. 54, 331-348. URL 
ANEXO

Tabla 6. Escenario 1 crédito otorgado por el FOVISSSTE considerando una tasa de interés efectiva anual del $10.25 \%$

Table 6. Scenario 1: Loan granted by the FOVISSSTE considering a $10.25 \%$ effective annual interest rate

\begin{tabular}{ccccc} 
Número de meses & $\begin{array}{c}\text { Pago por meses } \\
(\mathrm{MXN})\end{array}$ & $\begin{array}{c}\text { Intereses sobre el saldo insoluto } \\
(\mathrm{MXN})\end{array}$ & $\begin{array}{c}\text { Amortización } \\
(\mathrm{MXN})\end{array}$ & $\begin{array}{c}\text { Saldo Insoluto } \\
(\mathrm{MXN})\end{array}$ \\
\hline 0 & $\$ 0.00$ & $\$ 0.00$ & $\$ 0.00$ & $\$ 620000.00$ \\
\hline 1 & $\$ 6000.00$ & $\$ 5295.83$ & $\$ 704.17$ & $\$ 619295.83$ \\
\hline 2 & $\$ 6000.00$ & $\$ 5289.82$ & $\$ 710.18$ & $\$ 618585.65$ \\
\hline$\ldots$ & $\ldots$ & $\ldots$ & $\ldots$ & $\ldots$ \\
\hline 252 & $\$ 5396.09$ & $\$ 45.70$ & $\$ 5350.38$ & $\$ 0.00$ \\
\hline Total & $\$ 1511396.09$ & $\$ 891396.09$ & & \\
\hline
\end{tabular}

Tabla 7. Escenario 2 crédito otorgado por el FOVISSSTE considerando una tasa de interés efectiva anual del $10.25 \%$

Table 7. Scenario 2: Loan granted by the FOVISSSTE considering a $10.25 \%$ effective annual interest rate

\begin{tabular}{ccccc}
\hline Número de meses & $\begin{array}{c}\text { Pago por meses } \\
(\mathrm{MXN})\end{array}$ & $\begin{array}{c}\text { Intereses sobre el saldo insoluto } \\
(\mathrm{MXN})\end{array}$ & $\begin{array}{c}\text { Amortización } \\
(\mathrm{MXN})\end{array}$ & $\begin{array}{c}\text { Saldo Insoluto } \\
(\mathrm{MXN})\end{array}$ \\
\hline 0 & $\$ 0.00$ & $\$ 0.00$ & $\$ 0.00$ & $\$ 620000.00$ \\
\hline 1 & $\$ 6500.00$ & $\$ 5295.83$ & $\$ 1204.17$ & $\$ 618795.83$ \\
\hline 2 & $\$ 6500.00$ & $\$ 5285.55$ & $\$ 1214.45$ & $\$ 617581.38$ \\
\hline$\ldots$ & $\ldots$ & $\ldots$ & $\ldots$ & $\ldots$ \\
\hline 199 & $\$ 1492.51$ & $\$ 12.64$ & $\$ 1479.87$ & $\$ 0.00$ \\
\hline Total & $\$ 1288492.51$ & $\$ 668492.51$ & $\$ 620000.00$ & \\
\hline
\end{tabular}

Tabla 8. Escenario 3 crédito otorgado por el FOVISSSTE considerando una tasa de interés efectiva anual del $10.25 \%$

Table 8. Scenario 3: Loan granted by the FOVISSSTE considering a $10.25 \%$ effective annual interest rate

\begin{tabular}{ccccc}
\hline Número de meses & $\begin{array}{c}\text { Pago por meses } \\
(\mathrm{MXN})\end{array}$ & $\begin{array}{c}\text { Intereses sobre el saldo insoluto } \\
(\mathrm{MXN})\end{array}$ & $\begin{array}{c}\text { Amortización } \\
(\mathrm{MXN})\end{array}$ & $\begin{array}{c}\text { Saldo Insoluto } \\
(\mathrm{MXN})\end{array}$ \\
\hline 0 & $\$ 0.00$ & $\$ 0.00$ & $\$ 0.00$ & $\$ 620000.00$ \\
\hline 1 & $\$ 10000.00$ & $\$ 5295.83$ & $\$ 4704.17$ & $\$ 615295.83$ \\
\hline 2 & $\$ 10000.00$ & $\$ 5255.65$ & $\$ 4744.35$ & $\$ 610551.49$ \\
\hline$\ldots$ & $\ldots$ & $\ldots$ & $\ldots$ & $\ldots$ \\
\hline Total & $\$ 6666.25$ & $\$ 56.46$ & $\$ 6609.79$ & $\$ 0.00$ \\
\hline \multicolumn{5}{c}{ Fuente: elaboración propia exportando los valores del código a Excel. } \\
\hline
\end{tabular}


Tabla 9. Escenario 1 crédito bancario considerando la tasa mínima promedio de $10.95 \%$ efectiva anual Table 9. Scenario 1: Bank microcredit considering a $10.95 \%$ minimum average effective annual interest rate

\begin{tabular}{|c|c|c|c|c|}
\hline Número de meses & $\begin{array}{l}\text { Pago por meses } \\
\text { (MXN) }\end{array}$ & $\begin{array}{l}\text { Intereses sobre el saldo insoluto } \\
\qquad(\mathrm{MXN})\end{array}$ & $\begin{array}{l}\text { Amortización } \\
(\mathrm{MXN})\end{array}$ & $\begin{array}{l}\text { Saldo Insoluto } \\
\qquad(M X N)\end{array}$ \\
\hline 0 & $\$ 0.00$ & $\$ 0.00$ & $\$ 0.00$ & $\$ 620000.00$ \\
\hline 1 & $\$ 6000.00$ & $\$ 5657.50$ & $\$ 342.50$ & $\$ 619657.50$ \\
\hline 2 & $\$ 6000.00$ & $\$ 5654.37$ & $\$ 345.63$ & $\$ 619311.87$ \\
\hline$\ldots$ & $\ldots$ & $\ldots$ & $\ldots$ & $\ldots$ \\
\hline 316 & $\$ 1261.63$ & $\$ 11.41$ & $\$ 1250.22$ & $\$ 0.00$ \\
\hline Total & $\$ 1891261.63$ & $\$ 1271261.63$ & $\$ 620000.00$ & \\
\hline
\end{tabular}

Tabla 10. Escenario 2 crédito bancario considerando la tasa mínima promedio de $10.95 \%$ efectiva anual Table 10. Scenario 2: Bank microcredit considering a $10.95 \%$ minimum average effective annual interest rate

\begin{tabular}{ccccc}
\hline Número de meses & $\begin{array}{c}\text { Pago por meses } \\
(\mathrm{MXN})\end{array}$ & $\begin{array}{c}\text { Intereses sobre el saldo insoluto } \\
(\mathrm{MXN})\end{array}$ & $\begin{array}{c}\text { Amortización } \\
(\mathrm{MXN})\end{array}$ & $\begin{array}{c}\text { Saldo Insoluto } \\
(\mathrm{MXN})\end{array}$ \\
\hline 0 & $\$ 0.00$ & $\$ 0.00$ & $\$ 0.00$ & $\$ 620000.00$ \\
\hline 1 & $\$ 6500.00$ & $\$ 5657.50$ & $\$ 842.50$ & $\$ 619157.50$ \\
\hline 2 & $\$ 6500.00$ & $\$ 5649.81$ & $\$ 850.19$ & $\$ 618307.31$ \\
\hline$\ldots$ & $\ldots$ & $\ldots$ & $\ldots$ & $\ldots$ \\
\hline 225 & $\$ 6050.79$ & $\$ 54.71$ & $\$ 5996.08$ & $\$ 0.00$ \\
\hline Total & $\$ 1462$ 050.79 & $\$ 842050.79$ & $\$ 620000.00$ & \\
\hline
\end{tabular}

Tabla 11. Escenario 3 crédito bancario considerando la tasa mínima promedio de $10.95 \%$ efectiva anual Table 11. Scenario 3: Bank microcredit considering a $10.95 \%$ minimum average effective annual interest rate

\begin{tabular}{ccccc} 
Número de meses & $\begin{array}{c}\text { Pago por meses } \\
(\mathrm{MXN})\end{array}$ & $\begin{array}{c}\text { Intereses sobre el saldo insoluto } \\
(\mathrm{MXN})\end{array}$ & $\begin{array}{c}\text { Amortización } \\
(\mathrm{MXN})\end{array}$ & $\begin{array}{c}\text { Saldo Insoluto } \\
(\mathrm{MXN})\end{array}$ \\
\hline 0 & $\$ 0.00$ & $\$ 0.00$ & $\$ 0.00$ & $\$ 620000.00$ \\
\hline 1 & $\$ 10000.00$ & $\$ 5657.50$ & $\$ 4342.50$ & $\$ 615657.50$ \\
\hline 2 & $\$ 10000.00$ & $\$ 5617.87$ & $\$ 4382.13$ & $\$ 611275.37$ \\
\hline$\ldots$ & $\ldots$ & $\ldots$ & $\ldots$ & $\ldots$ \\
\hline Total & $\$ 9291.22$ & $\$ 74.97$ & $\$ 8216.24$ & $\$ 0.00$ \\
\hline \multicolumn{7}{c}{ Fuente: elaboración propia exportando los valores del código a Excel. } \\
\hline
\end{tabular}


Tabla 12. Escenario 1 crédito bancario considerando la tasa media promedio de $13.17 \%$ efectiva anual Table 12. Scenario 1: Bank microcredit considering a $13.17 \%$ average effective annual interest rate

\begin{tabular}{ccccc}
\hline Número de meses & $\begin{array}{c}\text { Pago por meses } \\
(\mathrm{MXN})\end{array}$ & $\begin{array}{c}\text { Intereses sobre el saldo insoluto } \\
(\mathrm{MXN})\end{array}$ & $\begin{array}{c}\text { Amortización } \\
(\mathrm{MXN})\end{array}$ & $\begin{array}{c}\text { Saldo Insoluto } \\
(\mathrm{MXN})\end{array}$ \\
\hline 0 & $\$ 0.00$ & $\$ 0.00$ & $\$ 0.00$ & $\$ 620000.00$ \\
\hline 1 & $\$ 10000.00$ & $\$ 6804.50$ & $\$ 3195.50$ & $\$ 616804.50$ \\
\hline 2 & $\$ 10000.00$ & $\$ 6769.43$ & $\$ 3230.57$ & $\$ 613573.93$ \\
\hline$\ldots$ & $\ldots$ & $\ldots$ & $\ldots$ & $\ldots$ \\
\hline 105 & $\$ 5198.59$ & $\$ 56.44$ & $\$ 5142.16$ & $\$ 0.00$ \\
\hline Total & $\$ 1045,198.59$ & $\$ 425198.59$ & $\$ 620000.00$ & \\
\hline \multicolumn{5}{r}{} \\
& Fuente: elaboración propia exportando los valores del código a Excel. &
\end{tabular}

Tabla 13. Escenario 1 crédito bancario considerando la tasa máxima promedio de $15.89 \%$ Table 13. Scenario 1: Bank microcredit considering a $15.89 \%$ maximum average interest rate

\begin{tabular}{ccccc}
\hline Número de meses & $\begin{array}{c}\text { Pago por meses } \\
(\mathrm{MXN})\end{array}$ & $\begin{array}{c}\text { Intereses sobre el saldo insoluto } \\
(\mathrm{MXN})\end{array}$ & $\begin{array}{c}\text { Amortización } \\
(\mathrm{MXN})\end{array}$ & $\begin{array}{c}\text { Saldo Insoluto } \\
(\mathrm{MXN})\end{array}$ \\
\hline 0 & $\$ 0.00$ & $\$ 0.00$ & $\$ 0.00$ & $\$ 620000.00$ \\
\hline 1 & $\$ 10000.00$ & $\$ 8209.83$ & $\$ 1790.17$ & $\$ 618209.83$ \\
\hline 2 & $\$ 10000.00$ & $\$ 8186.13$ & $\$ 1813.87$ & $\$ 616395.96$ \\
\hline$\ldots$ & $\ldots$ & $\ldots$ & $\ldots$ & $\ldots$ \\
\hline 131 & $\$ 7732.94$ & $\$ 101.06$ & $\$ 7631.88$ & $\$ 0.00$ \\
\hline Total & $\$ 1307732.94$ & $\$ 687732.94$ & $\$ 620000.00$ & \\
\hline \multicolumn{5}{r}{} \\
\hline
\end{tabular}

Tabla 14. Escenario 1 crédito otorgado por el INFONAVIT considerando una tasa de interés efectiva anual del $8.70 \%$

Table 14. Scenario 1: Loan granted by the INFONAVIT considering a $8.70 \%$ effective annual interest rate

\begin{tabular}{ccccc} 
Número de meses & $\begin{array}{c}\text { Pago por meses } \\
(\mathrm{MXN})\end{array}$ & $\begin{array}{c}\text { Intereses sobre el saldo insoluto } \\
(\mathrm{MXN})\end{array}$ & $\begin{array}{c}\text { Amortización } \\
(\mathrm{MXN})\end{array}$ & $\begin{array}{c}\text { Saldo Insoluto } \\
(\mathrm{MXN})\end{array}$ \\
\hline 0 & $\$ 0.00$ & $\$ 0.00$ & $\$ 0.00$ & $\$ 620000.00$ \\
\hline 1 & $\$ 5000.00$ & $\$ 4495.00$ & $\$ 505.00$ & $\$ 619495.00$ \\
\hline 2 & $\$ 5000.00$ & $\$ 4491.34$ & $\$ 508.66$ & $\$ 618986.34$ \\
\hline$\ldots$ & $\ldots$ & $\ldots$ & $\ldots$ & $\ldots$ \\
\hline 318 & $\$ 1856.32$ & $\$ 13.36$ & $\$ 1842.96$ & $\$ 0.00$ \\
\hline Total & $\$ 1586856.32$ & $\$ 966856.32$ & $\$ 620000.00$ & \\
\hline \multicolumn{5}{r}{} \\
& Fuente: elaboración propia exportando los valores del código a Excel.
\end{tabular}


Tabla 15. Escenario 2 crédito otorgado por el INFONAVIT considerando una tasa de interés efectiva anual del $8.80 \%$

Table 15. Scenario 2: Loan granted by the INFONAVIT considering a $8.80 \%$ effective annual interest rate

\begin{tabular}{ccccc} 
Número de meses & $\begin{array}{c}\text { Pago por meses } \\
(\mathrm{MXN})\end{array}$ & $\begin{array}{c}\text { Intereses sobre el saldo insoluto } \\
(\mathrm{MXN})\end{array}$ & $\begin{array}{c}\text { Amortización } \\
(\mathrm{MXN})\end{array}$ & $\begin{array}{c}\text { Saldo Insoluto } \\
(\mathrm{MXN})\end{array}$ \\
\hline 0 & $\$ 0.00$ & $\$ 0.00$ & $\$ 0.00$ & $\$ 620000.00$ \\
\hline 1 & $\$ 5000.00$ & $\$ 4546.67$ & $\$ 453.33$ & $\$ 619546.67$ \\
\hline 2 & $\$ 5000.00$ & $\$ 4543.34$ & $\$ 456.66$ & $\$ 619090.01$ \\
\hline$\ldots$ & $\ldots$ & $\ldots$ & $\ldots$ & $\ldots$ \\
\hline 329 & $\$ 2747.83$ & $\$ 20.00$ & $\$ 2727.83$ & $\$ 0.00$ \\
\hline Total & $\$ 1642,747.83$ & $\$ 1022,747.83$ & $\$ 620000.00$ & \\
\hline
\end{tabular}

Tabla 16. Escenario 3 crédito otorgado por el INFONAVIT considerando una tasa de interés efectiva anual del $9.00 \%$

Table 16. Scenario 3: Loan granted by the INFONAVIT considering a $9.00 \%$ effective annual interest rate

\begin{tabular}{ccccc} 
Número de meses & $\begin{array}{c}\text { Pago por meses } \\
(\mathrm{MXN})\end{array}$ & $\begin{array}{c}\text { Intereses sobre el saldo insoluto } \\
(\mathrm{MXN})\end{array}$ & $\begin{array}{c}\text { Amortización } \\
(\mathrm{MXN})\end{array}$ & $\begin{array}{c}\text { Saldo Insoluto } \\
(\mathrm{MXN})\end{array}$ \\
\hline 0 & $\$ 0.00$ & $\$ 0.00$ & $\$ 0.00$ & $\$ 620000.00$ \\
\hline 1 & $\$ 5000.00$ & $\$ 4650.00$ & $\$ 350.00$ & $\$ 619650.00$ \\
\hline 2 & $\$ 5000.00$ & $\$ 4647.38$ & $\$ 352.63$ & $\$ 619297.38$ \\
\hline$\ldots$ & $\ldots$ & $\ldots$ & $\ldots$ & $\ldots$ \\
\hline 356 & $\$ 4481.63$ & $\$ 33.36$ & $\$ 4448.27$ & $\$ 0.00$ \\
\hline Total & $\$ 1779481.63$ & $\$ 1$ 159 481.63 & $\$ 620000.00$ & \\
\hline
\end{tabular}

Tabla 17. Escenario 4 crédito otorgado por el INFONAVIT considerando una tasa de interés efectiva anual del $9.00 \%$

Table 17. Scenario 4: Loan granted by the INFONAVIT considering a $9.00 \%$ effective annual interest rate

\begin{tabular}{ccccc}
\hline Número de meses & $\begin{array}{c}\text { Pago por meses } \\
(\mathrm{MXN})\end{array}$ & $\begin{array}{c}\text { Intereses sobre el saldo insoluto } \\
(\mathrm{MXN})\end{array}$ & $\begin{array}{c}\text { Amortización } \\
(\mathrm{MXN})\end{array}$ & $\begin{array}{c}\text { Saldo Insoluto } \\
(\mathrm{MXN})\end{array}$ \\
\hline 0 & $\$ 0.00$ & $\$ 0.00$ & $\$ 0.00$ & $\$ 620000.00$ \\
\hline 1 & $\$ 6000.00$ & $\$ 4650.00$ & $\$ 1350.00$ & $\$ 618650.00$ \\
\hline 2 & $\$ 6000.00$ & $\$ 4639.88$ & $\$ 1360.13$ & $\$ 617289.88$ \\
\hline$\ldots$ & $\ldots$ & $\ldots$ & $\ldots$ & $\ldots$ \\
\hline 200 & $\$ 3798.50$ & $\$ 28.28$ & $\$ 3770.23$ & $\$ 0.00$ \\
\hline Total & $\$ 1197798.50$ & $\$ 577798.50$ & $\$ 620000.00$ & \\
\hline
\end{tabular}


Tabla 18. Escenario 5 crédito otorgado por el INFONAVIT considerando una tasa de interés efectiva anual del $9.10 \%$

Table 18. Scenario 5: Loan granted by the INFONAVIT considering a $9.10 \%$ effective annual interest rate

\begin{tabular}{|c|c|c|c|c|}
\hline Número de meses & $\begin{array}{l}\text { Pago por meses } \\
\text { (MXN) }\end{array}$ & $\begin{array}{l}\text { Intereses sobre el saldo insoluto } \\
\text { (MXN) }\end{array}$ & $\begin{array}{l}\text { Amortización } \\
(M X N)\end{array}$ & $\begin{array}{l}\text { Saldo Insolutc } \\
\quad(M X N)\end{array}$ \\
\hline 0 & $\$ 0.00$ & $\$ 0.00$ & $\$ 0.00$ & $\$ 620000.00$ \\
\hline 1 & $\$ 6000.00$ & $\$ 4701.67$ & $\$ 1298.33$ & $\$ 618701.67$ \\
\hline 2 & $\$ 6000.00$ & $\$ 4691.82$ & $\$ 1308.18$ & $\$ 617393.49$ \\
\hline$\ldots$ & $\ldots$ & $\ldots$ & $\ldots$ & $\ldots$ \\
\hline 203 & $\$ 3677.58$ & $\$ 27.68$ & $\$ 3649.91$ & $\$ 0.00$ \\
\hline Total & $\$ 1215677.58$ & $\$ 595677.58$ & $\$ 620000.00$ & \\
\hline
\end{tabular}

Tabla 19. Escenario 6 crédito otorgado por el INFONAVIT considerando una tasa de interés efectiva anual del $9.20 \%$

Table 19. Scenario 6: Loan granted by the INFONAVIT considering a $9.20 \%$ effective annual interest rate

\begin{tabular}{|c|c|c|c|c|}
\hline Número de meses & $\begin{array}{l}\text { Pago por meses } \\
(M X N)\end{array}$ & $\begin{array}{l}\text { Intereses sobre el saldo insoluto } \\
\text { (MXN) }\end{array}$ & $\begin{array}{l}\text { Amortización } \\
(M X N)\end{array}$ & $\begin{array}{l}\text { Saldo Insoluto } \\
\qquad(M X N)\end{array}$ \\
\hline 0 & $\$ 0.00$ & $\$ 0.00$ & $\$ 0.00$ & $\$ 620000.00$ \\
\hline 1 & $\$ 6000.00$ & $\$ 4753.33$ & $\$ 1246.67$ & $\$ 618753.33$ \\
\hline 2 & $\$ 6000.00$ & $\$ 4743.78$ & $\$ 1256.22$ & $\$ 617497.11$ \\
\hline$\ldots$ & $\ldots$ & $\ldots$ & $\ldots$ & $\ldots$ \\
\hline 206 & $\$ 4414.52$ & $\$ 33.59$ & $\$ 4380.93$ & $\$ 0.00$ \\
\hline Total & $\$ 1234,414.52$ & $\$ 614414.52$ & $\$ 620000.00$ & \\
\hline
\end{tabular}

Tabla 20. Escenario 7 crédito otorgado por el INFONAVIT considerando una tasa de interés efectiva anual del $9.20 \%$

Table 20. Scenario 7: Loan granted by the INFONAVIT considering a $9.20 \%$ effective annual interest rate

\begin{tabular}{ccccc}
\hline Número de meses & $\begin{array}{c}\text { Pago por meses } \\
(\mathrm{MXN})\end{array}$ & $\begin{array}{c}\text { Intereses sobre el saldo insoluto } \\
(\mathrm{MXN})\end{array}$ & $\begin{array}{c}\text { Amortización } \\
(\mathrm{MXN})\end{array}$ & $\begin{array}{c}\text { Saldo Insoluto } \\
(\mathrm{MXN})\end{array}$ \\
\hline 0 & $\$ 0.00$ & $\$ 0.00$ & $\$ 0.00$ & $\$ 620000.00$ \\
\hline 1 & $\$ 6500.00$ & $\$ 4753.33$ & $\$ 1746.67$ & $\$ 618253.33$ \\
\hline 2 & $\$ 6500.00$ & $\$ 4739.94$ & $\$ 1760.06$ & $\$ 616493.28$ \\
\hline$\ldots$ & $\ldots$ & $\ldots$ & $\ldots$ & $\ldots$ \\
\hline 173 & $\$ 389.06$ & $\$ 2.96$ & $\$ 386.10$ & $\$ 0.00$ \\
\hline Total & $\$ 1118,389.06$ & $\$ 498389.06$ & $\$ 620000.00$ & \\
\hline \multicolumn{5}{r}{} \\
\hline
\end{tabular}


Tabla 21. Escenario 8 crédito otorgado por el INFONAVIT considerando una tasa de interés efectiva anual del $9.30 \%$

Table 21. Scenario 8: Loan granted by the INFONAVIT considering a $9.30 \%$ effective annual interest rate

\begin{tabular}{ccccc} 
Número de meses & $\begin{array}{c}\text { Pago por meses } \\
(\mathrm{MXN})\end{array}$ & $\begin{array}{c}\text { Intereses sobre el saldo insoluto } \\
(\mathrm{MXN})\end{array}$ & $\begin{array}{c}\text { Amortización } \\
(\mathrm{MXN})\end{array}$ & $\begin{array}{c}\text { Saldo Insoluto } \\
(\mathrm{MXN})\end{array}$ \\
\hline 0 & $\$ 0.00$ & $\$ 0.00$ & $\$ 0.00$ & $\$ 620000.00$ \\
\hline 1 & $\$ 6000.00$ & $\$ 4805.00$ & $\$, 195.00$ & $\$ 618805.00$ \\
\hline 2 & $\$ 6000.00$ & $\$ 4795.74$ & $\$ 1204.26$ & $\$ 617600.74$ \\
\hline$\ldots$ & $\ldots$ & $\ldots$ & $\ldots$ & $\ldots$ \\
\hline 210 & $\$ 83.92$ & $\$ 0.65$ & $\$ 83.28$ & $\$ 0.00$ \\
\hline Total & $\$ 1254,083.92$ & $\$ 634083.92$ & $\$ 620000.00$ & \\
\hline \multicolumn{7}{r}{} & Fuente: elaboración propia exportando los valores del código a Excel. &
\end{tabular}

Tabla 22. Escenario 9 crédito otorgado por el INFONAVIT considerando una tasa de interés efectiva anual del $9.30 \%$

Table 22. Scenario 9: Loan granted by the INFONAVIT considering a $9.30 \%$ effective annual interest rate

\begin{tabular}{ccccc} 
Número de meses & $\begin{array}{c}\text { Pago por meses } \\
(\mathrm{MXN})\end{array}$ & $\begin{array}{c}\text { Intereses sobre el saldo insoluto } \\
(\mathrm{MXN})\end{array}$ & $\begin{array}{c}\text { Amortización } \\
(\mathrm{MXN})\end{array}$ & $\begin{array}{c}\text { Saldo Insoluto } \\
(\mathrm{MXN})\end{array}$ \\
\hline 0 & $\$ 0.00$ & $\$ 0.00$ & $\$ 0.00$ & $\$ 620000.00$ \\
\hline 1 & $\$ 6500.00$ & $\$ 4805.00$ & $\$ 1695.00$ & $\$ 618305.00$ \\
\hline 2 & $\$ 6500.00$ & $\$ 4791.86$ & $\$ 1708.14$ & $\$ 616596.86$ \\
\hline$\ldots$ & $\ldots$ & $\ldots$ & $\ldots$ & $\ldots$ \\
\hline 175 & $\$ 691.13$ & $\$ 5.32$ & $\$ 685.81$ & $\$ 0.00$ \\
\hline Total & $\$ 1131691.13$ & $\$ 511691.13$ & $\$ 620000.00$ & \\
\hline \multicolumn{5}{c}{} \\
\hline
\end{tabular}

Tabla 23. Escenario 10 crédito otorgado por el INFONAVIT considerando una tasa de interés efectiva anual del $9.40 \%$

Table 23. Scenario 10: Loan granted by the INFONAVIT considering a $9.40 \%$ effective annual interest rate

\begin{tabular}{ccccc} 
Número de meses & $\begin{array}{c}\text { Pago por meses } \\
(\mathrm{MXN})\end{array}$ & $\begin{array}{c}\text { Intereses sobre el saldo insoluto } \\
(\mathrm{MXN})\end{array}$ & $\begin{array}{c}\text { Amortización } \\
(\mathrm{MXN})\end{array}$ & $\begin{array}{c}\text { Saldo Insoluto } \\
(\mathrm{MXN})\end{array}$ \\
\hline 0 & $\$ 0.00$ & $\$ 0.00$ & $\$ 0.00$ & $\$ 620000.00$ \\
\hline 1 & $\$ 6000.00$ & $\$ 4856.67$ & $\$ 1143.33$ & $\$ 618856.67$ \\
\hline 2 & $\$ 6000.00$ & $\$ 4847.71$ & $\$ 1152.29$ & $\$ 617704.38$ \\
\hline$\ldots$ & $\ldots$ & $\ldots$ & $\$ 2764.20$ & $\$ 0.00$ \\
\hline 213 & $\$ 2785.85$ & $\$ 21.65$ & $\$ 620000.00$ & \\
\hline Total & $\$ 1274785.85$ & $\$ 654785.85$ & &
\end{tabular}


Tabla 24. Escenario 11 crédito otorgado por el INFONAVIT considerando una tasa de interés efectiva anual del $9.40 \%$

Table 24. Scenario 11: Loan granted by the INFONAVIT considering a $9.40 \%$ effective annual interest rate

\begin{tabular}{ccccc} 
Número de meses & $\begin{array}{c}\text { Pago por meses } \\
(\text { MXN) }\end{array}$ & $\begin{array}{c}\text { Intereses sobre el saldo insoluto } \\
(\mathrm{MXN})\end{array}$ & $\begin{array}{c}\text { Amortización } \\
(\mathrm{MXN})\end{array}$ & $\begin{array}{c}\text { Saldo Insoluto } \\
(\mathrm{MXN})\end{array}$ \\
\hline 0 & $\$ 0.00$ & $\$ 0.00$ & $\$ 0.00$ & $\$ 620000.00$ \\
\hline 1 & $\$ 6500.00$ & $\$ 4856.67$ & $\$ 1643.33$ & $\$ 618356.67$ \\
\hline 2 & $\$ 6500.00$ & $\$ 4843.79$ & $\$ 1656.21$ & $\$ 616700.46$ \\
\hline$\ldots$ & $\ldots$ & $\ldots$ & $\ldots$ & $\ldots$ \\
\hline 177 & $\$ 1487.73$ & $\$ 11.56$ & $\$ 1476.17$ & $\$ 0.00$ \\
\hline Total & $\$ 1145,487.73$ & $\$ 525487.73$ & $\$ 620000.00$ & \\
\hline \multicolumn{5}{r}{} \\
\hline
\end{tabular}

Tabla 25. Escenario 12 crédito otorgado por el INFONAVIT considerando una tasa de interés efectiva anual del $9.50 \%$

Table 25. Scenario 12: Loan granted by the INFONAVIT considering a $9.50 \%$ effective annual interest rate

\begin{tabular}{ccccc} 
Número de meses & $\begin{array}{c}\text { Pago por meses } \\
\text { (MXN) }\end{array}$ & $\begin{array}{c}\text { Intereses sobre el saldo insoluto } \\
\text { (MXN) }\end{array}$ & $\begin{array}{c}\text { Amortización } \\
(\mathrm{MXN})\end{array}$ & $\begin{array}{c}\text { Saldo Insoluto } \\
(\mathrm{MXN})\end{array}$ \\
\hline 0 & $\$ 0.00$ & $\$ 0.00$ & $\$ 0.00$ & $\$ 620000.00$ \\
\hline 1 & $\$ 6000.00$ & $\$ 4908.33$ & $\$ 1091.67$ & $\$ 618908.33$ \\
\hline 2 & $\$ 6000.00$ & $\$ 4899.69$ & $\$ 1100.31$ & $\$ 617808.02$ \\
\hline$\ldots$ & $\ldots$ & $\ldots$ & $\ldots$ & $\ldots$ \\
\hline 217 & $\$ 601.04$ & $\$ 4.72$ & $\$ 596.32$ & $\$ 0.00$ \\
\hline Total & $\$ 1296601.04$ & $\$ 676601.04$ & $\$ 620000.00$ & \\
\hline \multicolumn{5}{c}{ Fuente: elaboración propia exportando los valores del código a Excel. } \\
\hline
\end{tabular}

Tabla 26. Escenario 13 crédito otorgado por el INFONAVIT considerando una tasa de interés efectiva anual del $9.50 \%$

Table 26. Scenario 13: Loan granted by the INFONAVIT considering a $9.50 \%$ effective annual interest rate

\begin{tabular}{ccccc} 
Número de meses & $\begin{array}{c}\text { Pago por meses } \\
(\mathrm{MXN})\end{array}$ & $\begin{array}{c}\text { Intereses sobre el saldo insoluto } \\
(\mathrm{MXN})\end{array}$ & $\begin{array}{c}\text { Amortización } \\
(\mathrm{MXN})\end{array}$ & $\begin{array}{c}\text { Saldo Insoluto } \\
(\mathrm{MXN})\end{array}$ \\
\hline 0 & $\$ 0.00$ & $\$ 0.00$ & $\$ 0.00$ & $\$ 620000.00$ \\
\hline 1 & $\$ 6500.00$ & $\$ 4908.33$ & $\$ 1591.67$ & $\$ 618408.33$ \\
\hline 2 & $\$ 6500.00$ & $\$ 4895.73$ & $\$ 1604.27$ & $\$ 616804.07$ \\
\hline$\ldots$ & $\ldots$ & $\ldots$ & $\$$ & $\ldots$ \\
\hline 179 & $\$ 2810.97$ & $\$ 22.08$ & $\$ 0.00$ \\
\hline Total & $\$ 1159,810.97$ & $\$ 539810.97$ & $\$ 620000.00$ & \\
\hline
\end{tabular}


Tabla 27. Escenario 14 crédito otorgado por el INFONAVIT considerando una tasa de interés efectiva anual del $9.50 \%$

Table 27. Scenario 14: Loan granted by the INFONAVIT considering a $9.50 \%$ effective annual interest rate

\begin{tabular}{ccccc}
\hline Número de meses & $\begin{array}{c}\text { Pago por meses } \\
(\mathrm{MXN})\end{array}$ & $\begin{array}{c}\text { Intereses sobre el saldo insoluto } \\
(\mathrm{MXN})\end{array}$ & $\begin{array}{c}\text { Amortización } \\
(\mathrm{MXN})\end{array}$ & $\begin{array}{c}\text { Saldo Insoluto } \\
(\mathrm{MXN})\end{array}$ \\
\hline 0 & $\$ 0.00$ & $\$ 0.00$ & $\$ 0.00$ & $\$ 620000.00$ \\
\hline 1 & $\$ 10000.00$ & $\$ 4908.33$ & $\$ 5091.67$ & $\$ 614908.33$ \\
\hline 2 & $\$ 10000.00$ & $\$ 4868.02$ & $\$ 5131.98$ & $\$ 609776.36$ \\
\hline$\ldots$ & $\ldots$ & $\ldots$ & $\ldots$ & $\ldots$ \\
\hline Total & $\$ 855986.10$ & $\$ 47.02$ & $\$ 5939.08$ & $\$ 0.00$ \\
\hline \multicolumn{5}{c}{ Fuente: elaboración propia exportando los valores del código a Excel. } \\
\end{tabular}

Tabla 28. Escenario 15 crédito otorgado por el INFONAVIT considerando una tasa de interés efectiva anual del $10 \%$

Table 28. Scenario 15: Loan granted by the INFONAVIT considering a $10 \%$ effective annual interest rate

\begin{tabular}{ccccc} 
Número de meses & $\begin{array}{c}\text { Pago por meses } \\
(\mathrm{MXN})\end{array}$ & $\begin{array}{c}\text { Intereses sobre el saldo insoluto } \\
(\mathrm{MXN})\end{array}$ & $\begin{array}{c}\text { Amortización } \\
(\mathrm{MXN})\end{array}$ & $\begin{array}{c}\text { Saldo Insoluto } \\
(\mathrm{MXN})\end{array}$ \\
\hline 0 & $\$ 0.00$ & $\$ 0.00$ & $\$ 0.00$ & $\$ 620000.00$ \\
\hline 1 & $\$ 6000.00$ & $\$ 5166.67$ & $\$ 833.33$ & $\$ 619166.67$ \\
\hline 2 & $\$ 6000.00$ & $\$ 5159.72$ & $\$ 840.28$ & $\$ 618326.39$ \\
\hline$\ldots$ & $\ldots$ & $\ldots$ & $\$ 5211.67$ & $\$ 0.00$ \\
\hline 238 & $\$ 5255.10$ & $\$ 43.43$ & $\$ 620000.00$ & \\
\hline Total & $\$ 1427255.10$ & $\$ 807255.10$ & $\ldots$ &
\end{tabular}

Tabla 29. Escenario 16 crédito otorgado por el INFONAVIT considerando una tasa de interés efectiva anual del $10 \%$

Table 29. Scenario 16: Loan granted by the INFONAVIT considering a $10 \%$ effective annual interest rate

\begin{tabular}{ccccc} 
Número de meses & $\begin{array}{c}\text { Pago por meses } \\
(\mathrm{MXN})\end{array}$ & $\begin{array}{c}\text { Intereses sobre el saldo insoluto } \\
(\mathrm{MXN})\end{array}$ & $\begin{array}{c}\text { Amortización } \\
(\mathrm{MXN})\end{array}$ & $\begin{array}{c}\text { Saldo Insoluto } \\
(\mathrm{MXN})\end{array}$ \\
\hline 0 & $\$ 0.00$ & $\$ 0.00$ & $\$ 0.00$ & $\$ 620000.00$ \\
\hline 1 & $\$ 6500.00$ & $\$ 5166.67$ & $\$ 1333.33$ & $\$ 618666.67$ \\
\hline 2 & $\$ 6500.00$ & $\$ 5155.56$ & $\$ 1344.44$ & $\$ 617322.22$ \\
\hline$\ldots$ & $\ldots$ & $\ldots$ & $\$$ & $\ldots$ \\
\hline 191 & $\$ 5757.69$ & $\$ 47.58$ & $\$ 5710.10$ & $\$ 0.00$ \\
\hline Total & $\$ 1240757.69$ & $\$ 620757.69$ & $\$ 620000.00$ & \\
\hline
\end{tabular}


Tabla 30. Escenario 17 crédito otorgado por el INFONAVIT considerando una tasa de interés efectiva anual del $10 \%$

Table 30. Scenario 17: Loan granted by the INFONAVIT considering a 10\% effective annual interest rate

\begin{tabular}{ccccc}
\hline Número de meses & $\begin{array}{c}\text { Pago por meses } \\
(\mathrm{MXN})\end{array}$ & $\begin{array}{c}\text { Intereses sobre el saldo insoluto } \\
(\mathrm{MXN})\end{array}$ & $\begin{array}{c}\text { Amortización } \\
(\mathrm{MXN})\end{array}$ & $\begin{array}{c}\text { Saldo Insoluto } \\
(\mathrm{MXN})\end{array}$ \\
\hline 0 & $\$ 0.00$ & $\$ 0.00$ & $\$ 0.00$ & $\$ 620000.00$ \\
\hline 1 & $\$ 10000.00$ & $\$ 5166.67$ & $\$ 4833.33$ & $\$ 615166.67$ \\
\hline 2 & $\$ 10000.00$ & $\$ 5126.39$ & $\$ 4873.61$ & $\$ 610293.06$ \\
\hline$\ldots$ & $\ldots$ & $\ldots$ & $\ldots$ & $\ldots$ \\
\hline Total & $\$ 6098.57$ & $\$ 50.40$ & $\$ 6048.17$ & $\$ 0.00$ \\
\hline
\end{tabular}

Tabla 31. Salario Mensual de la clase Media Baja en México

Table 31. Monthly salary of low-income workers in Mexico

\begin{tabular}{ccccc}
\hline Año & SMVDF diario (MXN) & SMVDF mensual (MXN) & 2SMVDF mensual (MXN) & 3SMVDF mensual (MXN) \\
\hline 2015 & $\$ 70.1$ & $\$ 2103$ & $\$ 4206$ & $\$ 6309$ \\
\hline 2016 & $\$ 73.04$ & $\$ 2191.2$ & $\$ 4382.4$ & $\$ 6573.6$ \\
\hline 2017 & $\$ 80.04$ & $\$ 2401.2$ & $\$ 4802.4$ & $\$ 7203.6$ \\
\hline 2018 & $\$ 88.36$ & $\$ 2650.8$ & $\$ 5301.6$ & $\$ 7952.4$ \\
\hline 2019 & $\$ 102.68$ & $\$ 3080.4$ & $\$ 6160.8$ & $\$ 9241.2$ \\
\hline 2020 & $\$ 123.22$ & $\$ 3696.6$ & $\$ 7393.2$ & $\$ 11089.8$ \\
\hline
\end{tabular}

Fuente: elaboración propia con datos de la CONASAMI (2020).

\section{CÓDIGO}

Para tener una mejor comprensión del algoritmo, se denotarán las ecuaciones que el programa ocupa para calcular las tablas de amortización:

$$
r[y]=s[y-1] * q
$$

Donde r[y] representa el interés sobre el Saldo Insoluto del periodo actual, s[y-1] es el Saldo Insoluto de un periodo anterior, $y$ el periodo actual y $q$ la tasa de interés efectiva capitalizable.

$$
a[y]=p-r[y]
$$

$\mathrm{a}[\mathrm{y}]$ es la amortización del periodo actual, p es el pago por periodo y r[y]es el interés sobre el Saldo Insoluto del periodo actual.

$$
\begin{gathered}
s[y=0]=v p \\
s[y]=s[y-1]-a[y]
\end{gathered}
$$


$\mathrm{s}[\mathrm{y}]$ es el Saldo Insoluto del periodo actual, vp es el valor presente y $s[y-1]$ es el Saldo Insoluto de un periodo anterior.

Observando las fórmulas se puede concluir que si $\mathrm{p}<\mathrm{r}[\mathrm{y}]$, entonces la amortización será negativa, por lo que el Saldo Insoluto incrementará en lugar de disminuir, por lo tanto, la deuda se hará más grande.

También si desde el inicio se observa que $\mathrm{p}>\mathrm{r}[\mathrm{y}]$ y $\mathrm{p} \approx \mathrm{r}[\mathrm{y}]$, entonces la amortización periódica será muy pequeña, el Saldo Insoluto disminuirá muy poco y se tendrán demasiados periodos para que la deuda adquirida se encuentre completamente amortizada. El código del programa para amortizar una deuda que se trabajó en el software Dev c++, es el siguiente:

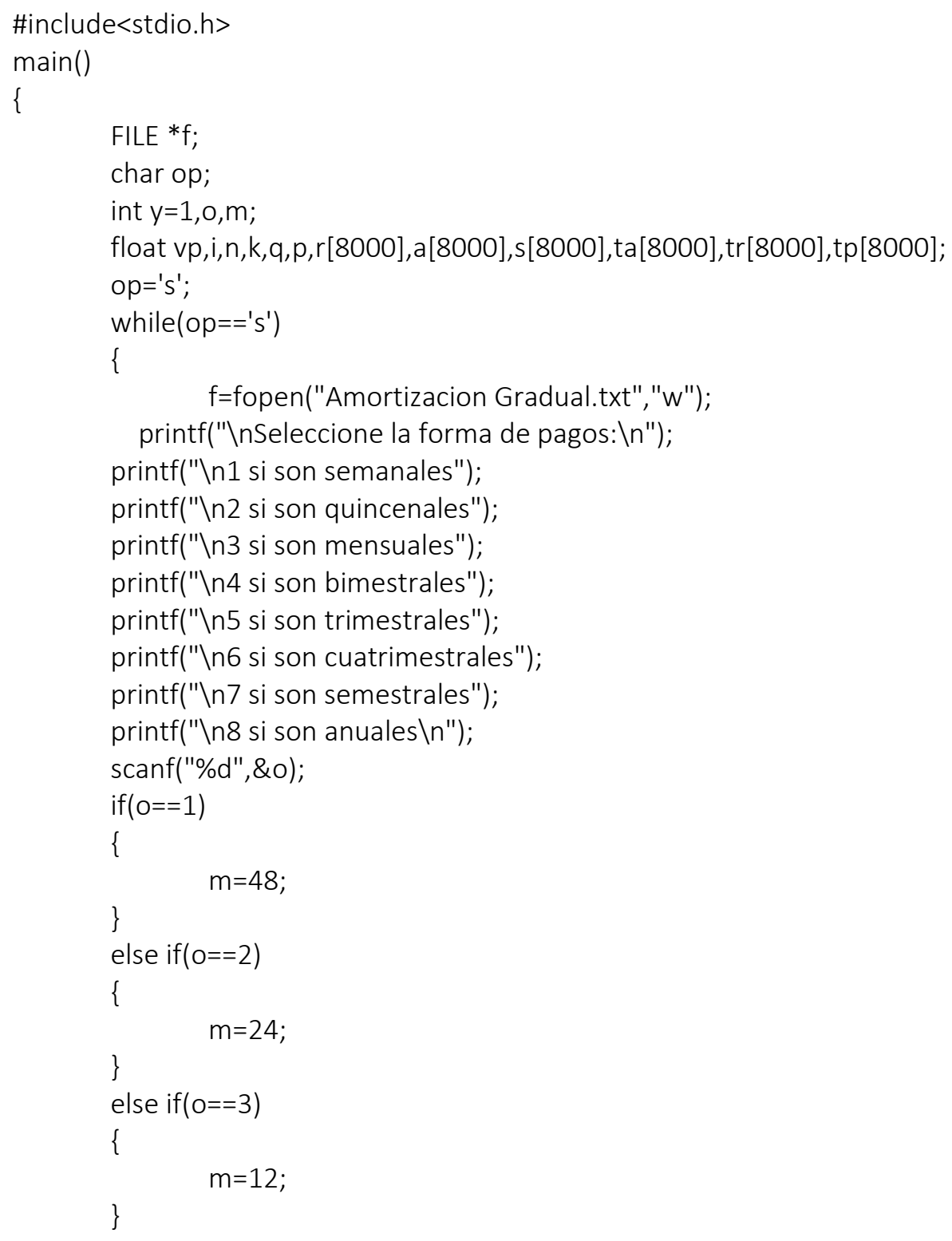




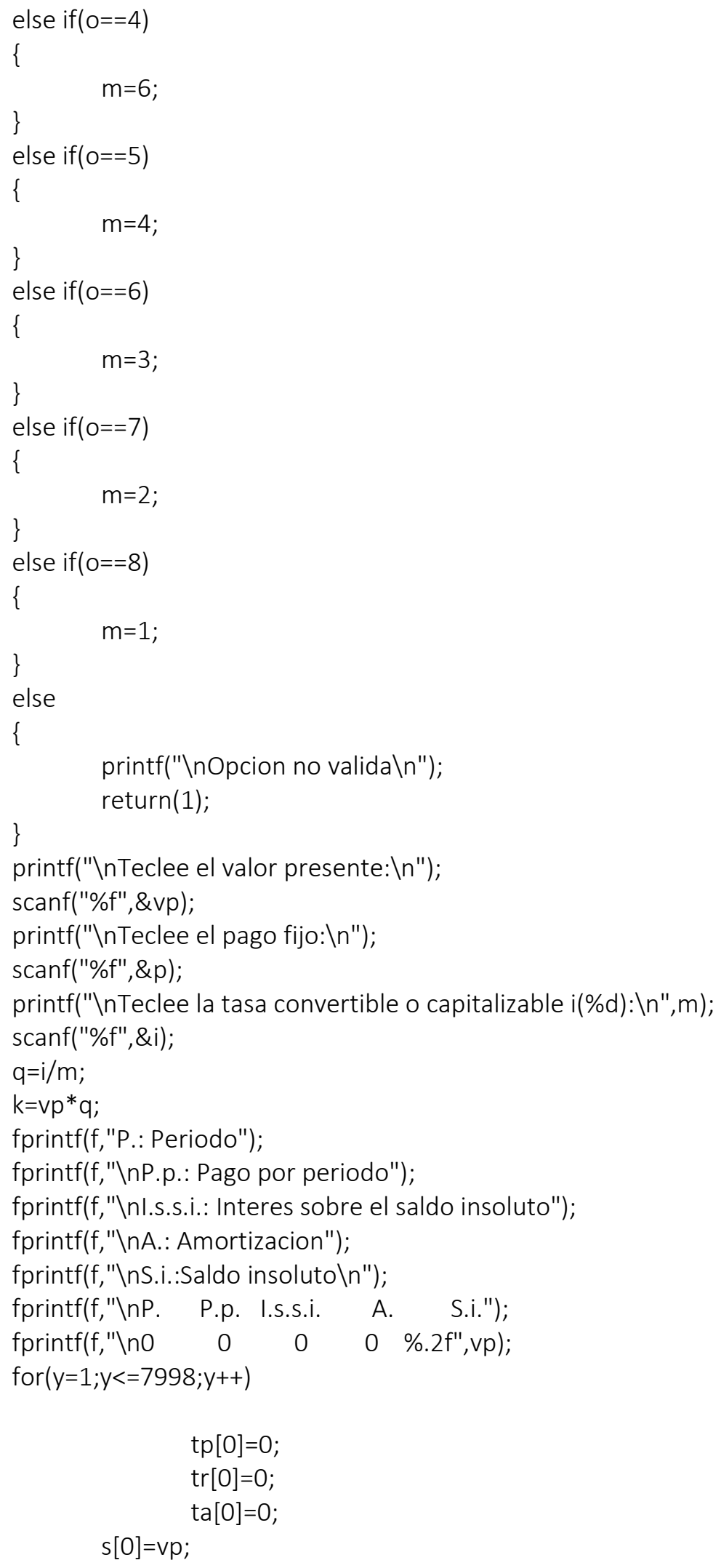




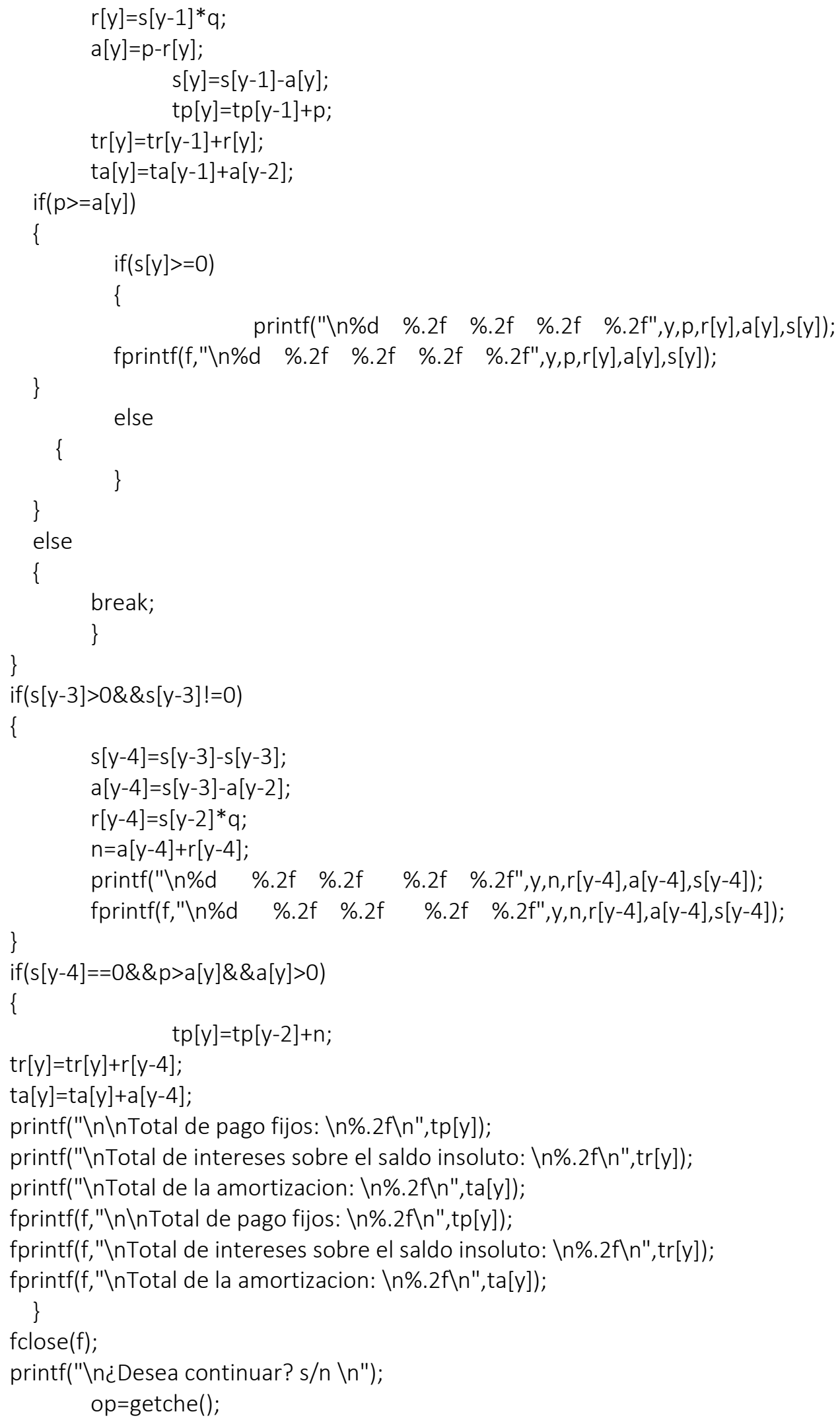


getche();

\}

\}

system("PAUSE"); 